\title{
miRDRN - miRNA Disease Regulatory Network: A tool for exploring disease and tissue-specific microRNA regulatory networks
}

\author{
Hsueh-Chuan Liu ${ }^{1}$, Yi-Shian Peng ${ }^{1}$, Hoong-Chien Lee ${ }^{\text {Corresp. 1,2 }}$ \\ 1 Department of Biomedical Sciences and Engineering, National Central University, Taoyuan City, Taiwan \\ 2 Department of Physics, Chung Yuan Christian University, Zhongli District, Taoyuan City, Taiwan \\ Corresponding Author: Hoong-Chien Lee \\ Email address: hclee12345@gmail.com
}

Background. miRNA regulates cellular processes by acting on specific target genes, and cellular processes proceed through multiple interactions often organized into pathways among genes and gene products. Hundreds of miRNAs and their target genes have been identified, as are many miRNA-disease associations. These, together with huge amounts of data on gene annotation, biological pathways, and protein-protein interactions are available in public databases. Here, using such data we built a database and web service platform, miRNA Disease Regulatory Network, or miRDRN, for users to construct disease and tissue-specific miRNA-protein regulatory networks, with which they may explore disease related molecular and pathway associations, or find new ones, and possibly discover new modes of drug action. Methods. Data on disease-miRNA association, miRNAtarget association and validation, gene-tissue association, gene-tumor association, biological pathways, human protein interaction, gene ID, gene ontology, gene annotation and product were collected from publicly available databases and integrated. A large set of miRNA target-specific regulatory sub-pathways (RSPs) having the form $\left(T, G_{1}, G_{2}\right)$ was built from the integrated data and stored, where $T$ is a miRNA-associated target gene, $G_{1}\left(G_{2}\right)$ is a gene/protein interacting with $T\left(G_{1}\right)$. Each sequence $\left(T, G_{1}, G_{2}\right)$ was assigned a $p$-value weighted by the participation of the three genes in molecular interactions and reaction pathways. Results. A web service platform, miRDRN (http://mirdrn.ncu.edu.tw/mirdrn/), was built. The database part of miRDRN currently stores $6,973,875 p$-valued RSPs associated with 116 diseases in 78 tissue types built from 207 diseases-associated miRNA regulating 389 genes. miRDRN also provides facilities for the user to construct disease and tissue-specific miRNA regulatory networks from RSPs it stores, and to download and/or visualize parts or all of the product. User may use miRDRN to explore a single disease, or a disease-pair to gain insights on comorbidity. As demonstrations, miRDRN was applied: to 
explore the single disease colorectal cancer (CRC), in which 26 novel potential CRC target genes were identified; to study the comorbidity of the disease-pair Alzheimer's diseaseType 2 diabetes (AD-T2D), in which 18 novel potential comorbid genes were identified; and, to explore possible causes that may shed light on recent failures of late-phase trials of anti-AD, BACE1 inhibitor drugs, in which genes downstream to BACE1 whose suppression may affect signal transduction were identified. 


\section{1 miRDRN - miRNA Disease Regulatory Network: A tool for}

2 exploring disease and tissue-specific microRNA regulatory

\section{3 networks}

4

5 Hsueh-Chuan Liu ${ }^{1}$, Yi-Shian Peng ${ }^{1}$ and Hoong-Chien Lee. ${ }^{1,2}$

6

7 'Department of Biomedical Sciences and Engineering, National Central University, Zhongli

8 District, Taoyuan City, 32001, Taiwan

9 2Department of Physics, Chung Yuan Christian University, Zhongli District, Taoyuan City, 10 32023, Taiwan

11

12 Corresponding Author:

13 Hoong-Chien Lee

14300 Zhongda Road, Zhongli District Taoyuan City, 32001, Taiwan

15 Email address: hclee12345@gmail.com 


\section{Abstract}

19

20

21

22

23

24

25

26

27

28

29

30

31

32

33

34

35

36

37

Background. miRNA regulates cellular processes by acting on specific target genes, and cellular processes proceed through multiple interactions often organized into pathways among genes and gene products. Hundreds of miRNAs and their target genes have been identified, as are many miRNA-disease associations. These, together with huge amounts of data on gene annotation, biological pathways, and protein-protein interactions are available in public databases. Here, using such data we built a database and web service platform, miRNA Disease Regulatory Network, or miRDRN, for users to construct disease and tissue-specific miRNA-protein regulatory networks, with which they may explore disease related molecular and pathway associations, or find new ones, and possibly discover new modes of drug action.

Methods. Data on disease-miRNA association, miRNA-target association and validation, genetissue association, gene-tumor association, biological pathways, human protein interaction, gene ID, gene ontology, gene annotation and product were collected from publicly available databases and integrated. A large set of miRNA target-specific regulatory sub-pathways (RSPs) having the form $\left(T, G_{1}, G_{2}\right)$ was built from the integrated data and stored, where $T$ is a miRNA-associated target gene, $G_{1}\left(G_{2}\right)$ is a gene/protein interacting with $T\left(G_{1}\right)$. Each sequence $\left(T, G_{1}, G_{2}\right)$ was assigned a $p$-value weighted by the participation of the three genes in molecular interactions and reaction pathways.

Results. A web service platform, miRDRN (http://mirdrn.ncu.edu.tw/mirdrn/), was built. The database part of miRDRN currently stores 6,973,875 p-valued RSPs associated with 116 diseases in 78 tissue types built from 207 diseases-associated miRNA regulating 389 genes. miRDRN also provides facilities for the user to construct disease and tissue-specific miRNA regulatory networks from RSPs it stores, and to download and/or visualize parts or all of the product. User may use miRDRN to explore a single disease, or a disease-pair to gain insights on comorbidity. As demonstrations, miRDRN was applied: to explore the single disease colorectal cancer (CRC), in which 26 novel potential CRC target genes were identified; to study the comorbidity of the disease-pair Alzheimer's disease-Type 2 diabetes (AD-T2D), in which 18 novel potential comorbid genes were identified; and, to explore possible causes that may shed light on recent failures of late-phase trials of anti-AD, $B A C E 1$ inhibitor drugs, in which genes downstream to $B A C E 1$ whose suppression may affect signal transduction were identified.

\section{(1)}


52 Keywords: Database, web service tool, disease-miRNA association, target-specific regulatory 53 pathway, disease and tissue-specific miRNA-protein regulatory network, disease target gene, 54 comorbidity gene, colorectal cancer, Alzheimer's disease, Type 2 diabetes, anti-AD BACE1 55 inhibitor drug 56 


\section{Introduction}

58 Protein-protein interactions (PPIs) are critical to almost all biological process, and a good

59 knowledge of the network of interacting proteins is crucial to understanding cellular mechanisms

60 [1]. Recent advances in biotechnology, such as high-throughput yeast two-hybrid screening, have 61 allowed scientists to build maps of proteome-wide PPI, or interactome. Conventionally, a PPI

62 map is a static network, in which each node represents a protein and an edge connecting two

63 proteins indicates that there is experimental evidence showing that, under certain circumstances,

64 the two proteins would interact. In reality, a PPI network (PPIN) should be viewed as a dynamic

65 entity: it is an interaction network that is intrinsically controlled by regulatory mechanisms and

66 changes with time and space [2], as determined by the physiological condition of the cell in

67 which the proteins reside. If there is a PPIN that includes all possible PPIs, then, under a specific

68 physiological condition only a specific sub-network of the PPIN is realized.

69 MicroRNAs (miRNAs) are small ( 22 nucleotides) noncoding regulatory RNA molecules in 70 plants, animals, and some viruses. In a process known as RNA interference (RNAi), a miRNA 71 regulates gene expression by destabilizing and/or disrupting the translation of fully or partially 72 sequenced mRNA [3, 4]. In this way a miRNA regulates the formation of all PPINs to which its 73 target is connected, and by extension all biological processes with which those PPINs are 74 involved. As well as acting as a tumor suppressor gene, a miRNA may also act as an oncogene, 75 say, by targeting a tumor suppressor gene [5]. The function of a specific biological process, or its 76 malfunction, such as associated with a disease, typically involves a complex composed of a set 77 of miRNA-regulated proteins, together with their interacting protein partners. The study of such 78 miRNA-protein complexes should be an integral part of understanding biological processes [6] 79 as well as diseases.

80

An understanding of the molecular and physio-pathological mechanisms of diseases is crucial for the design of disease preventive and therapeutic strategies. The combination of experimental and computational methods has led to the discovery of disease-related genes [7, 8]. An example is the causal relation connecting the malfunction causing mutations in the enzyme phenylalanine hydroxylase to the metabolic disorder Phenylketonuria [9]. Many human diseases cannot be attributed to single-gene malfunctions but arise from complex interactions among multiple genetic variants [10]. How a disease is caused and how it can be treated can be better studied on the basis of a body of knowledge including all associated genes and biological pathways involving those genes.

Diseases are usually defined by a set of phenotypes that are associated with various pathological processes and their mutual interactions. Some relations between phenotypes of different diseases 
91 may be understood on the basis of common underlying molecular processes [11], such as when

92 there are genes associated with both diseases. It has been shown that genes associated with the 93 same disorder encode proteins that have a strong tendency to interact with each other [12]. More 94 specifically, one may consider two diseases to be related if their metabolic reactions within a cell 95 share common enzymes [13]. Networks of PPIs have also been studied in the context of disease 96 interactions $[14,15]$.

97 Here, we report on a web service platform, miRNA Disease Regulatory Network, or miRDRN 98 (http://mirdrn.ncu.edu.tw/mirdrn/). The platform contains two parts, a database that stores a set 99 of newly constructed set of 6,973,875 p-valued target-specific regulatory sub-pathways (RSPs) 100 associated with 116 diseases in 78 tissue types built from 207 diseases-associated miRNA 101 regulating 389 genes; and a novel web-based tool that, using the RSPs stored in miRDRN and 102 information from miRNA-related databases, facilitates the construction and visualization of disease and tissue-specific miRNA-protein regulatory networks for user specified single diseases and, for comorbidity studies, disease-pairs. We demonstrate three applications of miRDRN: to explore the molecular and network properties of the single disease colorectal neoplasm; to study the comorbidity of the disease-pair AD-T2D; and, by using miRDRN to construct a miRNA regulatory sub-network centered on the gene $B A C E 1$, to look for insights that may explain why several anti-AD, $B A C E 1$ inhibiting drugs that failed recent late-phase trials worsened conditions of treatment groups. We believe findings from miRDRN, even exploratory in nature, may potentially lead to the identification of new drug targets and new understanding in modes of drug action.

112

\section{Materials and Methods}

\section{Data integration} miRDRM integrated data from several existing database on disease-miRNA association, miRNA-target gene association, gene ontology, biological pathway, and protein-protein interaction. For disease-specific cases disease-associated miRNAs and targets were obtained from HMDD [16] (v2.0, http://www.cuilab.cn/hmdd). For non-disease specific cases, miRNA/siRNA and targets were obtained from TarBase [17] (v7.0, http://www.microrna.gr/tarbase). In disease-specific cases, the optional filter requiring miRNAtarget association be assay validated used TarBase data; the filter excludes miRNA-target pairs appearing in HMDD but not in TarBase (if and when this happens). Gene-tissue associations were taken from NCBI-UniGene [18] (https://www.ncbi.nlm.nih.gov/unigene); regulatory sub-

124 pathway associations with known pathways from KEGG [19] (http://www.genome.jp/kegg); 
125 gene-tumor associations from TAG [20] (http://www.binfo.ncku.edu.tw/TAG); OMIM IDs of

126 target genes and genes on regulatory networks from NCBI-OMIM [18]

127 (https://www.ncbi.nlm.nih.gov/omim); gene IDs and transcription factor and/or receptor from

128 NCBI-GeneBank [18] (https://www.ncbi.nlm.nih.gov/genbank); data on human protein-protein

129 interaction from BioGRID [21] (https://thebiogrid.org/); and gene ontology, gene annota-tion and

130 gene product information from GO [22] (http://geneontology.org/). (Table 1)

131

132

\section{Construction of miRNA-associated target-specific regulatory sub-pathways}

133 Consider a linked sequence $\left(M, T, G_{1}, G_{2}\right)$ (Figure 1$)$, where $M$ is a miRNA, $T$ is its regulatory

134 target gene, $G_{1}$ is a gene whose encoded protein $\left(p_{1}\right)$ interacts (according to PPI data) with the

135 protein $\left(p_{T}\right)$ encoded by $T$, and $G_{2}$ is a gene whose encoded protein $\left(p_{2}\right)$ interacts with $p_{1}$. In what

136 follows, when there is little risk of misunderstanding, the same symbol will be used to represent

137 a gene or the protein it encodes. We call the sequence $\left(T, G_{1}, G_{2}\right)$ a target-specific regulatory

138 sub-pathway, or simply a regulatory sub-pathway (RSP), and $\left(M, T, G_{1}, G_{2}\right)$ a miRNA-specific

139 RSP (MRSP). Given a target gene $T$, we use PPI data from BioGRID to collect all RSPs by

140 extending from $T$ two levels of interaction.

141

142 Jaccard score of a regulatory sub-pathway

143 Jaccard similarity coefficients [23] were used to score the RSPs, based on the assumption that

144 there is a tendency for two directly interacting proteins to participate in the same set of biological 145 processes or share the same set of molecular functions. Given two sets $S 1$ and $S 2$ (in the current 146 application, a set will be either a list of biological processes (BP) or a list of molecular functions 147 (MF), both according to GO), the Jaccard (similarity) coefficient (JC) of $S 1$ and $S 2$ is defined as,

$$
J C(S 1, S 2)=\frac{|S 1 \cap S 2|}{|S 1 \cup S 2|}
$$

149

150

151

152

153

154

155

Where $\cup$ is the union (of two sets), $\cap$ is the intersection, and $|\mathrm{Z}|$ is the cardinality of $\mathrm{Z}$. $J C$, which ranges from 0 to 1 , is a quantitative measure of the similarity between two sets. For example, when $S 1=\{a, b, c\}$ and $S 2=\{b, c, d\}, J C(S 1, S 2)=2 / 4=0.5$.

Let $\left(T, G_{1}, G_{2}\right)$ be an RSP as defined in the previous section and denote by $[G]$ the set of biological processes (or pathways) $[19,22]$ that involve the gene $G$. We define the Jaccard score, or $J S$, of RSP as,

$$
J S_{\mathrm{X}}\left(T, G_{1}, G_{2}\right)=\frac{1}{2}\left(J C\left([T]_{\mathrm{X}},\left[G_{1}\right]_{\mathrm{X}}\right)+J C\left(\left[G_{1}\right]_{\mathrm{X}},\left[G_{2}\right]_{\mathrm{X}}\right)\right)
$$


156 Where X may be BP or MF. If the pair $[T]$ and $\left[G_{1}\right]$ do not share a common term, then the

157 corresponding $J C$ has a zero value; similarly for the pair $\left[G_{1}\right]$ and $\left[G_{2}\right]$. In either case the RSP is

158 considered to be not viable and discarded. In other words, miRDRN excludes any RSP with zero

$159 J C$ score.

160

161

$P$-value of a regulatory sub-pathway

162

163

164

165

166

167

168

169 and

170

A $p$-value for an RSP $\left(T, G_{1}, G_{2}\right)$ was assigned as follows. Let the total number of BP (or MF, as the case may be) terms be $\mathrm{N}$, and the number of terms in $[T],\left[G_{1}\right],\left[G_{2}\right],[T] \cap\left[G_{1}\right],\left[G_{1}\right] \cap\left[G_{2}\right]$ be $x, y, z, n_{1}$, and $n_{2}$, respectively, then the $p$-values, $P_{1}$ and $P_{2}$, for $\left(T, G_{1}\right)$ and $\left(G_{1}, G_{2}\right)$ are respectively

171 The $p$-value for the RSP was set to be the greater of $P_{1}$ and $P_{2}$.

172

173

174

175

176

177

178

179

180

181

182

183

184

185

$$
P_{1}=\frac{C_{n_{1}}^{N} C_{x-n_{1}}^{N-n_{1}} C_{y-n_{1}}^{N-x}}{C_{x}^{N} C_{y}^{N}}
$$

and

\section{Assembly and storage of target-specific regulatory sub-pathways}

A union set of miRNA-associated target genes were collected from HMDD and TarBase and for every target a complete set of RSPs, with BP- and MF-type $J C$ scores and $p$-values assigned, was assembled. The entire set of RSPs for all targets was stored in miRDRN.

\section{Construction of disease-specific miRNA regulatory network}

A user-initiated construction of a disease-specific miRNA regulatory network (RRN) proceeds as follows. Step 1. Select a disease. Step 2. Collect from HMDD all miRNAs ( $M$ 's) and target genes associated with the disease. Step 3. For each $M$ and each of its targets retrieve from miRDRN storage all target-specific RSPs, thus forming a set of miRNA-specific RSP (MRSPs). The union of the sets of MRSPs over all M's is the set of disease-specific MRSPs for the selected disease. Step 4. Construct the disease-specific RRN from the set of disease-specific MRSPs by linking all unlinked pairs of genes/proteins if they have interaction according to BioGRID (Figure 2). 
187

188

189

\section{Results}

190

miRNA Disease Regulatory Network (miRDRN) - A database and web service platform

191

We built miRDRN (http://mirdrn.ncu.edu.tw/mirdrn/), a web-based service that allows the user

192

to construct a disease and tissue-specific, $p$-valued, miRNA-protein regulatory network, or

193 miRNA regulatory network (RRN). The current version of miRDRN contains $6,973,875 p$ -

194 valued target-specific RSPs constructed through 389 miRNA-regulated genes from 207 diseases-

195

196 associated miRNAs associated with 116 diseases (Table 2).

197

\section{Comparison of miRDRN with other miRNA related databases}

198

A number of databases and/or web service platforms on miRNA-related topics are publicly available (Table 3). Aside from HMDD and TarBase on which miRDRN was built (Table 1), PhenomiR [24] is a database on disease-miRNA association, miRwayDB [25] is a database on

201 disease-miRNA-target and target-KEGG term association, and miRPathDB [26] is a database on miRNA-pathway association. New and unique as a database, miRDRN stores the $6,973,875 p$ valued target-specific RSPs it has assembled (Table 2). As a web service platform miRDRN is a tool that facilitates the construction and visualization of disease-specific RRNs using these RSPs

205 in combination with resources from HMDD, TarBase and several other databases (Table 1).

\section{Brief description of usage of miRDRN}

miRDRN is reasonably user friendly; its many features are easily discovered by user exploration. Here we give a brief description of its main features.

User may use miRDRN to explore a single disease, or the comorbidity of a disease-pair. In the course of either type of study, all relevant miRNAs, genes, and RSPs are made accessible to the user in tabulated form, and RRNs in the form of interactive maps, both of which may be downloaded by the user. Often a map is too large for practical visualization, and in such a case the user may use options such as setting a $p$-value cut-off, or requiring a specific gene to be present in the map, or both, to obtain a partial RRN.

216 The entrance interface of miRDRN (http://mirdrn.ncu.edu.tw/mirdrn/) asks the user to select 217 "Single Search" to explore a single disease (or miRNA/siRNA) or "Comorbidity Search" to explore the comorbidity of a disease-pair (Figure 3). The user is then asked to specify the disease or disease-pair to be explored and tissue/tumor types, and $p$-value threshold for RSP evaluation, 
220 and to click on (or not) several optional filters, respectively on targets and on RSPs. The filter on

221 miRNA targets allows the user to admit only targets positively validated by the seven direct

222 experimental methods: HITS-CLIP, PAR-CLIP, IMPACT-Seq, CLASH, Luciferase Reporter

223 Assay, 3LIFE, and Genetic Testing [17]; filters on RSP allow the user to select only those RSPs

224 with some or all of the proteins to be cancer related (Figure 4). The user may then click on

225 "Query" to start the computation. Tabulated results of disease-associated miRNAs and their

226 target genes (Figure 5), a multi-page list of all RSPs (Figure 6) and, in the case of Comorbidity

227 Search, a list of all comorbid genes (Figure 7) will then automatically appear. After the first,

228 automatic iteration, the user may reduce the size of the RSP-list by using the "Gene filter" and

229 "Show top ... sub-pathways" options (Figure 6). The next interface (Figure 8), in ready mode on

230 first appearance, waits for the user to select one of three network layouts: "Tree", "Circle", or

231 "Radial". After "Go" is clicked on, the platform displays an interactive map showing the RRN

232 built from RSPs selected by user-specified options (Figure 8). When the mouse is placed on a

233 node (a miRNA or a gene) on the map a small pop-up window opens to show the name of the

234 node/gene and the number of other nodes it is linked to, and annotation on the node from GO,

235 OMIM, KEGG, and GeneBank databases.

236

237 Discussion

238 Here we demonstrate the utility of miRDRN by presenting three applications.

239

240

241

242

243

244

245

246

247

248

249

250

251

252

253

254

\section{Case 1. A single disease study of colorectal neoplasm}

Here we demonstrate a single disease application of miRDRN. On the query interface select "colorectal neoplasms" (or colorectal cancer, CRC), tissue type "colorectal tumor", pathway ranking by "Jaccard index (MF)", and p-value < "0.001", and no option on target genes or RSP. The result yielded 33 miRNAs and 37 target genes (if the option "miRNA target experimental validation is positive and direct" on the query interface was selected then there would be 20 miRNAs and 23 target genes (Figure 5)), and 45,565 RSPs involving 3,079 genes (reduced to 2,111 RSPs and 1,650 genes when target is restricted to being "positive and direct" and cancer related (Figure 6)) (Table 4).

By default, the interface "target-specific regulatory sub-pathways" (Figure 6) lists all the constructed RSPs, namely all 45,565 of them in the present case and, if requested, would present a map including all the RSPs which, however, would be impractical to visualize, not to say interact with. On the same interface are two options for displaying/using a smaller RSP set: "Gene filter", where the user can restrict the set to only those RSPs containing a specified gene; and "Show top ... sub-pathways", where the user can ask for only the top-N

PeerJ reviewing PDF | (2019:04:36918:1:1:NEW 14 Jun 2019) 
255

256

257

258

259

260

261

262

263

264

265

266

267

268

269

270

271

272

273

274

275

276

277

278

279

280

281

282

283

284

285

286

287

288

289

290

RSPs having the smallest $p$-values be listed and used for network construction. The interface "Disease specific miRNA regulatory network" then allows the user to choose one among the layouts "Tree", "Circle", and "Radial". Here a tree-map, with several disconnected parts, built from the top-70 RSPs is shown (Figure 9).

The largest connected sub-RRN, or "Network-1" (Figure 10), is composed of six miRNAs targeting four genes connected to 52 other genes, (Table 5). Of the 56 genes in Network-1, 22 have known CRC connections (CORECG database, http://lms.snu.edu.in/corecg) [27], and 26 others have references linking them either directly or indirectly to CRC [28-55] (Table 6). Among these, TNIK [34] and TNK2 [54] have been used as drug targets for CRC treatment. We consider the remaining eight genes - PRKACA, MAP3K12, LRRK1, RIOK2, OXSR1, CDK17, EIF2AK1, TSSK4 - to be potential novel CRC-related genes. Noticeably, Network-1 has two parts, one 28 nodes (five miRNAs targeting three genes) and the other 34 nodes (one miRNA targeting one gene), connected by a single link, or PPI. The three types of genes, known CRC-related, reference-supported, and potential CRC-related, are more or less proportionately distributed in these two parts.

The "Gene filter" option (Figure 6) allows the user to focus on a specific gene in RRN construction. As example, TNK2, a key drug target for the treatment of metastatic CRC [54], was selected as the filter, together with the "Show top 70 RSPs" option. The result was a nine-node sub-RRN: the target gene $A X L$ regulated by three miRNAs - hsa-mir-199b, hsamir-34a, hsa-mir-199a - and linked (by PPI) to $T N K 2$, itself linked to four other genes AXL(OCG), MAGI3, HSP90AB2P, MERTK(OCG), KAT8 (Figure 11).

Case 2. A Comorbidity study of the disease-pair Alzheimer's disease-Type 2 diabetes (AD-T2D)

Recent studies suggest a possible AD-T2D comorbidity. Known pathophysiological factors shared by $\mathrm{AD}$ and T2D include insulin, cholesterol, $\beta$-amyloid aggregation and tau [56]. High cholesterol level impacts $\beta$-amyloid formation in the brain [57]; abnormal insulin function, a key factor of T2D and related disorders [58], increases the risk for AD [59]; cardiovascular risk factors such as high cholesterol and hypertension are common to T2D and $\mathrm{AD}$ [60]. Evidences connecting AD to impaired function of insulin/IGF suggested AD might be viewed as a new type, "type 3", of diabetes [61]. However, another study claims T2D to be associated with cerebrovascular but not Alzheimer neuropathology [62]. Here, we demonstrate a two-disease application of miRDRN. After logging onto miRDRN's entry interface (Figure 3), click on "Comorbidity Search" to see a new interface urging the user to 
291

292

293

294

295

296

297

298

299

300

301

302

303

304

305

306

307

308

309

310

311

312

313

314

315

316

317

318

319

320

321

322

323

324

325

326

select two diseases; for "Disease 1", "Alzheimer Disease" (AD) and tissue type "brain" were selected and for "Disease 2", "Type 2" (which stands for T2D) and tissue type "pancreas". Pathway ranking by "Jaccard index (MF)", and $p$-value $<$ " 0.005 " for both diseases were selected. Both AD and T2D are complex diseases and share aging for a risk factor; accumulated evidence indicates a connection between these two diseases at the molecular level [63]. For this case miRDRN yielded, for AD (T2D), three (one) associated-miRNAs, three (one) targeted genes, 644 (3908) RSPs, involving 633 (2187) genes (Table 7). Because $\mathrm{AD}$ and T2D did not have any common associated-miRNA target gene, they had distinct sets of RSPs. The 500 genes common to the two sets of RSPs ( 25 of which are shown in Figure 7) are significantly enriched in three KEGG terms: hsa03040:Spliceosome ( $p$ value $=0.00549)$, hsa03018:RNA degradation $(p$-value $=0.00802)$, and hsa03022:Basal transcription factors ( $p$-value $=0.00415)$. Abnormality of spliceosome has been reported in both $\mathrm{AD}[64]$ and T2D [65] patients. Among the comorbid genes, 8 - ALOX5, APP, BIN1, $C H G B, V W F, N E F L, L E T M D 1, C E L F 1$ - were identified as known AD target genes [66, 67, 68] and 14 - TCF7L2, APOA1, VWF, CDKN2B, CAT, ITGB2, ISL1, POLD3, APP, $N F K B I B, G N A 12, D E D D, L D L R, P R K A B 1$ - as known T2D target genes [69], APP and $V W F$ are known targets of both diseases (Table 8). With the exception of three - LEMD1, POLD3, GNA12, the comorbidity of all the others have literature support (Table 8).

\section{Case 3. A sub-RRN centered on the AD-associated gene $B A C E 1$}

In recent years a number of anti-AD drugs designed on the basis of the amyloid-beta $(A \beta)$ hypothesis of $A D$, which holds that $A \beta$ aggregate in the brain is the main causative factor of $\mathrm{AD}$, failed late-phase trials. These include the $\gamma$-secretase inhibitor Semagacestat [101] and two BACE1 inhibitors, Verubecestat [102] and Atabecestat [103]. In all three cases treatment groups scored worse than the control group on the ADCS-ADL (Alzheimer's Disease Cooperative Study Activities of Daily Living Inventory) functional measure and reported more anxiety, depression, and sleep problems than controls. In a "Single Search" application on AD (tissue, brain; $p$-value threshold, 0.005), we had miRDRN construct a partial RRN (Gene filter, $B A C E 1$; Show top 70 sub-pathways; Network layout, Radial) centered on $B A C E 1$, which is a regulatory target of hsa-mir-195. The result shows the genes PSEN1, NCSTN, RANBP9, PLSCR1, MMP2, and FURIN to be immediately downstream to BACE1 in the RRN (Figure 12). PSEN1 and NCSTN encode proteins that are, respectively, catalytic and essential subunits of the $\gamma$-secretase complex; suppression of these genes are presumably the purpose of $B A C E 1$ inhibition. On the other hand, $R A N B P 9$ encodes a protein that facilitates the progression of mitosis in developing neuroepithelial cells [104]; PLSCRI encodes a protein that acts in the control of 
327

328

329

330

331

332

\section{Conclusion}

334

335

336

337

338

339

340

341

342

343

344

345

346

347

348

349

350

351

352

353

354

355

356

357

358

359

360

\section{Abbreviations}

OCG: Oncogene

360 PPIN: PPI network

361 RSP: Target-specific regulatory sub-pathway

intracellular calcium homeostasis and has a central role in signal transduction [105]; MMP2 encodes a protein that promotes neural progenitor cell migration [106]. Suppression of these genes (by $B A C E 1$ inhibition) may therefore adversely affect signal transduction and the nerve system, and could be part of the reason why Semagacestat, Verubecestat, and Atabecestat worsened the ADCS-ADL functional measure of treatment groups.

This work describes miRDRN (http://mirdrn.ncu.edu.tw/mirdrn/), composed of a new database on target-specific regulatory sub-pathways (RSPs) and a web service platform that allows the user to use the stored RSPs to construct disease and tissue-specific miRNA regulatory networks (RRNs), which may aid the user to explore disease related molecular and pathway associations, or find new ones. As demonstration, miRDRN was applied to study the single disease CRC, where 34 potential target genes were identified, 26 of which have literature support; to study the comorbidity of the disease-pair AD-T2D, where 20 potential novel AD-T2D comorbid genes were identified, 17 of which have literature support; and to construct a partial miRNA regulatory sub-network centered on the AD-associated gene $B A C E 1$, which in turn suggests a possible explanation why, in late-phase trials that ended in failure, several $\gamma / \beta$-secretase inhibiting antiAD drugs worsened the functional measure of treatment groups. We believe that findings from miRDRN, even exploratory in nature, may potentially lead to the identification of new drug targets and new understanding in modes of drug action.

AD: Alzheimer's disease

BioGrid: Biological General Repository for Interaction Datasets

CRG: Cancer related gene

GO: Gene Ontology database

HMDD: Human microRNA and Disease Associations Database

KEGG: Kyoto Encyclopedia of Genes and Genomes

miRDRN: miRNA Disease Regulatory Network database and web service platform

MRSP: miRNA-specific regulatory sub-pathway

59 PPI: protein-protein interaction 
362 RRN: Disease-specific miRNA regulatory network 363 T2D: Type 2 Diabetes

364 TarBase: Database on miRNA:mRNA interactions

365 TSG: Tumor suppressor gene

366

367

368 


\section{References}

370 1. Rual JF, Venkatesan K, Hao T, Hirozane-Kishikawa T, Dricot A, Li N, Berriz G, Gibbons

371

372

373

374

375

376

377

378

379

380

381

382

383

384

385

386

387

388

389

390

391

392

393

394

395

396

397

398

399

400

401

402

403

G, Dreze M, Ayivi-Guedehoussou N, Klitgord N, Simon C, Boxem M, Milstein S, Rosenberg J, Goldberg DS, Zhang LV, Wong SL, Franklin G, Li S, Albala JS, Lim J, Fraughton C, Llamosas E, Cevik S, Bex C, Lamesch P, Sikorski RS, Vandenhaute J, Zoghbi HY, Smolyar A, Bosak S, Sequerra R, Doucette-Stamm L, Cusick ME, Hill DE, Roth FP, Vidal M. Towards a proteome-scale map of the human protein-protein interaction network. Nature. 2005, 437: 1173-1178.

2. LIANG H, LI WH. MicroRNA regulation of human protein-protein interaction network. RNA. 2007, 13: 1402-1408.

3. Bartel DP. MicroRNAs: target recognition and regulatory functions. Cell. 2009, 136(2): $215-233$.

4. Landgraf P, Rusu M, Sheridan R, Sewer A, Iovino N, Aravin A, Pfeffer S, Rice A, Kamphorst AO, Landthaler M, Lin C, Socci ND, Hermida L, Fulci V, Chiaretti S, Foà R, Schliwka J, Fuchs U, Novosel A, Müller RU, Schermer B, Bissels U, Inman J, Phan Q, Chien M, Weir DB, Choksi R, De Vita G, Frezzetti D, Trompeter HI, Hornung V, Teng G, Hartmann G, Palkovits M, Di Lauro R, Wernet P, Macino G, Rogler CE, Nagle JW, Ju J, Papavasiliou FN, Benzing T, Lichter P, Tam W, Brownstein MJ, Bosio A, Borkhardt A, Russo JJ, Sander C, Zavolan M, Tuschl T. A mammalian microRNA expression atlas based on small RNA library sequencing. Cell. 2007, 129(7): 1401-14.

5. Zhang W, Dahlberg JE, Tam W. MicroRNAs in tumorigenesis: a primer. Am J Pathol. 2007, 171(3): 728-38.

6. Hsu CW, Juan HF, Huang HC. Characterization of microRNA-regulated protein-protein interaction network. Proteomics. 2008, 8(10): 1975-9.

7. Botstein D, Risch N. Discovering genotypes underlying human phenotypes: past successes for mendelian disease, future approaches for complex disease. Nature Genetics. 2003, 33: $228-237$.

8. Kann MG. Advances in translational bioinformatics: computational approaches for the hunting of disease genes. Brief Bioinform. 2010; 11: 96-110.

9. Scriver CR, Waters PJ. Monogenic traits are not simple: lessons from phenylketonuria. Trends Genet. 1999, 15: 267-272.

10. Hirschhorn JN, Daly MJ. Genome-wide association studies for common diseases and complex traits. Nat Rev Genet. 2005, 6: 95-108.

11. Barabási AL, Gulbahce N, Loscalzo J. Network medicine: a network-based approach to human disease. Nat Rev. Genet. 2011; 12(1): 56-68. 
404

405

406

407

408

409

410

411

412

413

414

415

416

417

418

419

420

421

422

423

424

425

426

427

428

429

430

431

432

433

434

435

436

437

438

439

12. Goh KI, Cusick ME, Valle D, Childs B, Vidal M, Barabási AL. The human disease network. Proc Natl Acad Sci U S A. 2007, 104(21): 8685-90.

13. Lee DS, Park J, Kay KA, Christakis NA, Oltvai ZN, Barabási AL. The implications of human metabolic network topology for disease comorbidity. Proc Natl Acad Sci U S A. 2008, 105(29): 9880-5.

14. Ideker T, Sharan R. Protein networks in disease. Genome Res. 2008, 18(4): 644-52.

15. Lim J, Hao T, Shaw C, Patel AJ, Szabó G, Rual JF, Fisk CJ, Li N, Smolyar A, Hill DE, et al. A protein-protein interaction network for human inherited ataxias and disorders of Purkinje cell degeneration. Cell. 2006, 125(4): 801-14.

16. Li Y, Qiu C, Tu J, Geng B, Yang J, Jiang T, Cui Q. HMDD v2.0: a database for experimentally supported human microRNA and disease associations. Nucleic Acids Res. 2014, 42: D1070-4.

17. Vlachos IS, Paraskevopoulou MD, Karagkouni D, Georgakilas G, Vergoulis T, Kanellos I, Anastasopoulos IL, Maniou S, Karathanou K, Kalfakakou D, et al. DIANA-TarBase v7.0: indexing more than half a million experimentally supported miRNA:mRNA interactions. Nucleic Acids Res. 2015, 43: D153-9.

18. NCBI Resource Coordinators. Database resources of the National Center for Biotechnology Information. Nucleic Acids Res. 2018, 46(D1): D8-D13.

19. Kanehisa M, Furumichi M, Tanabe M, Sato Y, Morishima K. KEGG: new perspectives on genomes, pathways, diseases and drugs. Nucleic Acids Res. 2017, 45(D1): D353-D361.

20. Chen JS, Hung WS, Chan HH, Tsai SJ, Sun HS. In silico identification of oncogenic potential of fyn-related kinase in hepatocellular carcinoma. Bioinformatics. 2013, 29(4): 420-7.

21. Chatr-Aryamontri A, Breitkreutz BJ, Heinicke S, Boucher L, Winter A, Stark C, Nixon J, Ramage L, Kolas N, O'Donnell L, Reguly T, Breitkreutz A, Sellam A, Chen D, Chang C, Rust J, Livstone M, Oughtred R, Dolinski K, Tyers M. The BioGRID interaction database: 2013 update. Nucleic Acids Res. 2013, 41: D816-23.

22. Ashburner M, Ball CA, Blake JA, Botstein D, Butler H, Cherry JM, Davis AP, Dolinski K, Dwight SS, Eppig JT, et al. Gene ontology: tool for the unification of biology. The Gene Ontology Consortium. Nat Genet. 2000, 25(1): 25-9.

23. Ng KL, Liu HC, Lee SC. ncRNAppi-a tool for identifying disease-related miRNA and siRNA targeting pathways. Bioinformatics. 2009, 25(23): 3199-201.

24. Ruepp A, Kowarsch A, Theis F. PhenomiR: microRNAs in human diseases and biological processes. Methods Mol Biol. 2012, 822: 249-60.

25. Das SS, Saha P, Chakravorty N. miRwayDB: a database for experimentally validated microRNA-pathway associations in pathophysiological conditions. Database (Oxford). 
440

441

442

443

444

445

446

447

448

449

450

451

452

453

454

455

456

457

458

459

460

461

462

463

464

465

466

467

468

469

470

471

472

473

474

475

2018, 2018.

26. Backes C, Kehl T, Stöckel D, Fehlmann T, Schneider L, Meese E, Lenhof HP, Keller A. miRPathDB: a new dictionary on microRNAs and target pathways. Nucleic Acids Res. 2017, 45(D1): D90-D96.

27. Agarwal R, Kumar B, Jayadev M, Raghav D, Singh A. CoReCG: a comprehensive database of genes associated with colon-rectal cancer. Database (Oxford). 2016, 2016.

28. Kang MH, Moon SU, Sung JH, Kim JW, Lee KW, Lee HS, Lee JS, Kim JH. Antitumor Activity of HM781-36B, alone or in Combination with Chemotherapeutic Agents, in Colorectal Cancer Cells. Cancer Res Treat. 2016, 48(1): 355-64.

29. Sirvent A, Bénistant C, Pannequin J, Veracini L, Simon V, Bourgaux JF, Hollande F, Cruzalegui F, Roche S. Src family tyrosine kinases-driven colon cancer cell invasion is induced by Csk membrane delocalization. Oncogene. 2010, 29(9): 1303-15.

30. Jeong D, Kim H, Kim D, Ban S, Oh S, Ji S, Kang D, Lee H, Ahn TS, Kim HJ, et al. Protein kinase, membrane-associated tyrosine/threonine 1 is associated with the progression of colorectal cancer. Oncol Rep. 2018, 39(6): 2829-2836.

31. Xie T, D' Ario G, Lamb JR, Martin E, Wang K, Tejpar S, Delorenzi M, Bosman FT, Roth $\mathrm{AD}$, Yan $\mathrm{P}$, et al. A comprehensive characterization of genome-wide copy number aberrations in colorectal cancer reveals novel oncogenes and patterns of alterations. PLoS One. 2012, 7(7): e42001.

32. Wu S, Wu F, Jiang Z. Identification of hub genes, key miRNAs and potential molecular mechanisms of colorectal cancer. Oncol Rep. 2017, 38(4): 2043-2050.

33. Xiang Z, Wang S, Xiang Y. Up-regulated microRNA499a by hepatitis B virus induced hepatocellular carcinogenesis via targeting MAPK6. PLoS One. 2014, 9(10): e111410.

34. Masuda M, Yamada T. The emergence of TNIK as a therapeutic target for colorectal cancer. Expert Opin Ther Targets. 2017, 21(4): 353-355.

35. Ali RH, Marafie MJ, Bitar MS, Al-Dousari F, Ismael S, Bin Haider H, Al-Ali W, Jacob SP, Al-Mulla F. Gender-associated genomic differences in colorectal cancer: clinical insight from feminization of male cancer cells. Int J Mol Sci. 2014, 15(10): 17344-65.

36. Yun CW, Kim S, Lee JH, Lee SH. Melatonin Promotes Apoptosis of Colorectal Cancer Cells via Superoxide-mediated ER Stress by Inhibiting Cellular Prion Protein Expression. Anticancer Res. 2018, 38(7): 3951-3960.

37. Vázquez-Cedeira M, Lazo PA. Human VRK2 (vaccinia-related kinase 2) modulates tumor cell invasion by hyperactivation of NFAT1 and expression of cyclooxygenase-2. J Biol Chem. 2012, 287(51): 42739-50.

38. Zhang YJ, Dai Q, Sun DF, Xiong H, Tian XQ, Gao FH, Xu MH, Chen GQ, Han ZG, Fang JY. mTOR signaling pathway is a target for the treatment of colorectal cancer. Send to Ann 
476

477

478

479

480

481

482

483

484

485

486

487

488

489

490

491

492

493

494

495

496

497

498

499

500

501

502

503

504

505

506

507

508

509

510

511

Surg Oncol. 2009, 16(9): 2617-28.

39. Csukasi F, Duran I, Barad M, Barta T, Gudernova I, Trantirek L, Martin JH, Kuo CY, Woods J, Lee H, et al. The PTH/PTHrP-SIK3 pathway affects skeletogenesis through altered mTOR signaling. Sci Transl Med. 2018, 10(459).

40. Rey C, Faustin B, Mahouche I, Ruggieri R, Brulard C, Ichas F, Soubeyran I, Lartigue L, De Giorgi F. The MAP3K ZAK, a novel modulator of ERK-dependent migration, is upregulated in colorectal cancer. Oncogene. 2016, 35(24): 3190-200.

41. Goyal P, Behring A, Kumar A, Siess W. Identifying and characterizing a novel protein kinase STK35L1 and deciphering its orthologs and close-homologs in vertebrates. PLoS One. 2009, 4(9): e6981.

42. Sabir SR, Sahota NK, Jones GD, Fry AM. Loss of Nek11 Prevents G2/M Arrest and Promotes Cell Death in HCT116 Colorectal Cancer Cells Exposed to Therapeutic DNA Damaging Agents. PLoS One. 2015, 10(10): e0140975.

43. Bjerrum JT, Nielsen OH, Riis LB, Pittet V, Mueller C, Rogler G, Olsen J. Transcriptional analysis of left-sided colitis, pancolitis, and ulcerative colitis-associated dysplasia. Inflamm Bowel Dis. 2014, 20(12): 2340-52.

44. Hanna DL, Loupakis F, Yang D, Cremolini C, Schirripa M, Li M, Matsusaka S, Berger MD, Miyamoto Y, Zhang W, et al. Prognostic Value of ACVRL1 Expression in Metastatic Colorectal Cancer Patients Receiving First-line Chemotherapy With Bevacizumab: Results From the Triplet Plus Bevacizumab (TRIBE) Study. Clin Colorectal Cancer. 2018, 17(3): e471-e488.

45. Record CJ, Chaikuad A, Rellos P, Das S, Pike AC, Fedorov O, Marsden BD, Knapp S, Lee WH. Structural comparison of human mammalian ste20-like kinases. PLoS One. 2010, 5(8): e11905.

46. Zhou JK, Zheng YZ, Liu XS, Gou Q, Ma R, Guo CL, Croce CM, Liu L, Peng Y. ROR1 expression as a biomarker for predicting prognosis in patients with colorectal cancer. Oncotarget. 2017, 8(20): 32864-32872.

47. Gong H, Fang L, Li Y, Du J, Zhou B, Wang X, Zhou H, Gao L, Wang K, Zhang J. miR-873 inhibits colorectal cancer cell proliferation by targeting TRAF5 and TAB1. Oncol Rep. 2018, 39(3): 1090-1098.

48. Yuan WC, Pepe-Mooney B, Galli GG, Dill MT, Huang HT, Hao M, Wang Y, Liang H, Calogero RA, Camargo FD. NUAK2 is a critical YAP target in liver cancer. Nat Commun. 2018, 9(1): 4834.

49. Kim ST, Ahn TJ, Lee E, Do IG, Lee SJ, Park SH, Park JO, Park YS, Lim HY, Kang WK, et al. Exploratory biomarker analysis for treatment response in KRAS wild type metastatic colorectal cancer patients who received cetuximab plus irinotecan. BMC Cancer. 2015, 15: 
512747.

513 50. Li BQ, Huang T, Zhang J, Zhang N, Huang GH, Liu L, Cai YD. An ensemble prognostic

514

515

516

517

518

519

520

521

522

523

524

525

526

527

528

529

530

531

532

533

534

535

536

537

538

539

540

541

542

543

544

545

546

547 model for colorectal cancer. Send to PLoS One. 2013, 8(5): e63494.

51. Guo H, Hu X, Ge S, Qian G, Zhang J. Regulation of RAP1B by miR-139 suppresses human colorectal carcinoma cell proliferation. Int J Biochem Cell Biol. 2012, 44(9): 1465-72.

52. Peng H, Luo J, Hao H, Hu J, Xie SK, Ren D, Rao B. MicroRNA-100 regulates SW620 colorectal cancer cell proliferation and invasion by targeting RAP1B. Oncol Rep. 2014, 31(5): 2055-62.

53. Alonso MH, Aussó S, Lopez-Doriga A, Cordero D, Guinó E, Solé X, Barenys M, de Oca J, Capella G, Salazar R, Sanz-Pamplona R, Moreno V. Comprehensive analysis of copy number aberrations in microsatellite stable colon cancer in view of stromal component. $\mathrm{Br} \mathrm{J}$ Cancer. 2017, 117(3): 421-431.

54. Qi L, Ding Y. TNK2 as a key drug target for the treatment of metastatic colorectal cancer. Int J Biol Macromol. 2018, 119: 48-52.

55. Jin DH, Lee J, Kim KM, Kim S, Kim DH, Park J. Overexpression of MAPK15 in gastric cancer is associated with copy number gain and contributes to the stability of c-Jun. Oncotarget. 2015, 6(24): 20190-203.

56. Akter K, Lanza EA, Martin SA, Myronyuk N, Rua M, Raffa RB. Diabetes mellitus and Alzheimer's disease: shared pathology and treatment? Br J Clin Pharmacol. 2011, 71(3): 365-76.

57. Reed B, Villeneuve S, Mack W, DeCarli C, Chui HC, Jagust W. Associations between serum cholesterol levels and cerebral amyloidosis. JAMA Neurol. 2014, 71(2): 195-200.

58. Basu R, Chandramouli V, Dicke B, Landau B, Rizza R. Obesity and type 2 diabetes impair insulin-induced suppression of glycogenolysis as well as gluconeogenesis. Diabetes. 2005, 54(7): 1942-8.

59. Rönnemaa E, Zethelius B, Sundelöf J, Sundström J, Degerman-Gunnarsson M, Berne C, Lannfelt L, Kilander L. Impaired insulin secretion increases the risk of Alzheimer disease. Neurology. 2008, 71(14): 1065-71.

60. Kivipelto M, Ngandu T, Fratiglioni L, Viitanen M, Kåreholt I, Winblad B, Helkala EL, Tuomilehto J, Soininen H, Nissinen A. Obesity and vascular risk factors at midlife and the risk of dementia and Alzheimer disease. Arch Neurol. 2005, 62(10): 1556-60.

61. Lester-Coll N, Rivera EJ, Soscia SJ, Doiron K, Wands JR, de la Monte SM. Intracerebral streptozotocin model of type 3 diabetes: relevance to sporadic Alzheimer's disease. J Alzheimer's Dis. 2006, 9(1): 13-33.

62. Abner EL, Nelson PT, Kryscio RJ, Schmitt FA, Fardo DW, Woltjer RL, et al. Diabetes is associated with cerebrovascular but not Alzheimer neuropathology. Alzheimers Dement. 
548

549

550

551

552

553

554

555

556

557

558

559

560

561

562

563

564

565

566

567

568

569

570

571

572

573

574

575

576

577

578

579

580

581

582

583

2016, 12(8): 882-889.

63. Ahmed F, Ansari JA, Ansari ZE, Alam Q, Gan SH, Kamal MA, Ahmad E. A molecular bridge: connecting type 2 diabetes and Alzheimer's disease. CNS Neurol Disord Drug Targets. 2014, 13(2): 312-21.

64. Love JE, Hayden EJ, Rohn TT. Alternative splicing in Alzheimer's Disease. J Parkinsons Dis Alzheimers Dis. 2015, 2(2): 6.

65. Dlamini Z, Mokoena F, Hull R. Abnormalities in alternative splicing in diabetes: therapeutic targets. J Mol Endocrinol. 2017, 59(2): R93-R107.

66. Bertram L, McQueen MB, Mullin K, Blacker D, Tanzi RE. Systematic meta-analyses of Alzheimer disease genetic association studies: the AlzGene database. Nat Genet. 2007,39(1): 17-23.

67. Sun J, Feng X, Liang D, Duan Y, Lei H. Down-regulation of energy metabolism in Alzheimer's disease is a protective response of neurons to the microenvironment. $\mathrm{J}$ Alzheimers Dis. 2012, 28(2): 389-402.

68. Bai Z, Han G, Xie B, Wang J, Song F, Peng X, Lei H. AlzBase: an integrative database for gene dysregulation in Alzheimer's disease. Mol Neurobiol. 2016, 53(1): 310-319.

69. Dai HJ, Wu JC, Tsai RT, Pan WH, Hsu WL. T-HOD: a literature-based candidate gene database for hypertension, obesity and diabetes. Database (Oxford). 2013, 2013: bas061.

70. Postula M, Janicki PK, Rosiak M, Eyileten C, Zaremba M, Kaplon-Cieslicka A, Sugino S, Kosior DA, Opolski G, Filipiak KJ, Mirowska-Guzel D. Targeted deep resequencing of ALOX5 and ALOX5AP in patients with diabetes and association of rare variants with leukotriene pathways. Exp Ther Med. 2016, 12(1): 415-421.

71. Nejatian N, Penna-Martinez M, Steinhilber D, Badenhoop K. The association between vitamin D and the arachidonate 5-lipoxygenase (ALOX-5) gene polymorphism in type 2 diabetes. Diabetologie und Stoffwechsel. 2015, 10-P205.

72. Heemskerk MM, Giera M, Bouazzaoui FE, Lips MA, Pij1 H, van Dijk KW, van Harmelen V. Increased PUFA Content and 5-Lipoxygenase Pathway Expression Are Associated with Subcutaneous Adipose Tissue Inflammation in Obese Women with Type 2 Diabetes. Nutrients. 2015, 7(9): 7676-90.

73. Greenbaum L, Ravona-Springer R, Lubitz I, Schmeidler J, Cooper I, Sano M, Silverman JM, Heymann A, Beeri MS. Potential contribution of the Alzheimer's disease risk locus BIN1 to episodic memory performance in cognitively normal Type 2 diabetes elderly. Eur Neuropsychopharmacol. 2016, 26(4): 787-95.

74. Horn S, Kirkegaard JS, Hoelper S, Seymour PA, Rescan C, Nielsen JH, Madsen OD, Jensen JN, Krüger M, Grønborg M, Ahnfelt-Rønne J. Research Resource: A Dual Proteomic Approach Identifies Regulated Islet Proteins During $\beta$-Cell Mass Expansion In Vivo. Mol 
584

585

586

587

588

589

590

591

592

593

594

595

596

597

598

599

600

601

602

603

604

605

606

607

608

609

610

611

612

613

614

615

616

617

618

619

Endocrinol. 2016, 30(1): 133-43.

75. Wu DA, Bu X, Warden CH, Shen DD, Jeng CY, Sheu WH, Fuh MM, Katsuya T, Dzau VJ, Reaven GM, et al. Quantitative trait locus mapping of human blood pressure to a genetic region at or near the lipoprotein lipase gene locus on chromosome 8p22. J Clin Invest. 1996, 97(9): 2111-8.

76. Celikbilek A, Tanik N, Sabah S, Borekci E, Akyol L, Ak H, Adam M, Suher M, Yilmaz N. Elevated neurofilament light chain (NFL) mRNA levels in prediabetic peripheral neuropathy. Mol Biol Rep. 2014, 41(6): 4017-22.

77. Verma SK, Deshmukh V, Liu P, Nutter CA, Espejo R, Hung ML, Wang GS, Yeo GW, Kuyumcu-Martinez MN. Reactivation of fetal splicing programs in diabetic hearts is mediated by protein kinase C signaling. J Biol Chem. 2013, 288(49): 35372-86.

78. Belanger K, Nutter CA, Li J, Tasnim S, Liu P, Yu P, Kuyumcu-Martinez MN. CELF1 contributes to aberrant alternative splicing patterns in the type 1 diabetic heart. Biochem Biophys Res Commun. 2018, 503(4): 3205-3211.

79. Blom ES, Wang Y, Skoglund L, Hansson AC, Ubaldi M, Lourdusamy A, Sommer WH, Mielke M, Hyman BT, Heilig M, et al. Increased mRNA Levels of TCF7L2 and MYC of the Wnt Pathway in Tg-ArcSwe Mice and Alzheimer's Disease Brain. Int J Alzheimers Dis. 2010, 2011: 936580.

80. Včelák J, Vejražková D, Vaňková M, Lukášová P, Bradnová O, Hálková T, Bešt’ák J, Andělová K, Kvasničková H, Hoskovcová P, et al. T2D risk haplotypes of the TCF7L2 gene in the Czech population sample: the association with free fatty acids composition. Physiol Res. 2012, 61(3): 229-40.

81. Arefin AS, Mathieson L, Johnstone D, Berretta R, Moscato P. Unveiling clusters of RNA transcript pairs associated with markers of Alzheimer's disease progression. PLoS One. 2012, 7(9): e45535.

82. Riise J, Plath N, Pakkenberg B, Parachikova A. Aberrant Wnt signaling pathway in medial temporal lobe structures of Alzheimer's disease. J Neural Transm (Vienna). 2015, 122(9): 1303-18.

83. Vollbach H, Heun R, Morris CM, Edwardson JA, McKeith IG, Jessen F, Schulz A, Maier W, Kölsch H. APOA1 polymorphism influences risk for early-onset nonfamiliar AD. Ann Neurol. 2005, 58(3): 436-41.

84. Raygani AV, Rahimi Z, Kharazi H, Tavilani H, Pourmotabbed T. Association between apolipoprotein E polymorphism and serum lipid and apolipoprotein levels with Alzheimer's disease. Neurosci Lett. 2006, 408(1): 68-72.

85. Lin Q, Cao Y, Gao J. Decreased expression of the APOA1-APOC3-APOA4 gene cluster is associated with risk of Alzheimer's disease. Drug Des Devel Ther. 2015, 9: 5421-31. 
620 86. Pallàs M, Verdaguer E, Jordà EG, Jiménez A, Canudas AM, Camins A. Flavopiridol: an 621 antitumor drug with potential application in the treatment of neurodegenerative diseases. 622 Med Hypotheses. 2005, 64(1): 120-3.

623 87. Gsell W, Conrad R, Hickethier M, Sofic E, Frölich L, Wichart I, Jellinger K, Moll G, 624 Ransmayr G, Beckmann H, et al. Decreased catalase activity but unchanged superoxide 625 $6261995,64(3): 1216-23$. dismutase activity in brains of patients with dementia of Alzheimer type. J Neurochem.

627

88. Lovell MA, Ehmann WD, Butler SM, Markesbery WR. Elevated thiobarbituric acid-

628

629

630

631

632

633

634

635

636

637

638

639

640

641

642

643

644

645

646

647

648

649

650

651

652

653

654

655

90. Mizwicki MT, Liu G, Fiala M, Magpantay L, Sayre J, Siani A, Mahanian M, Weitzman R, Hayden EY, Rosenthal MJ, et al. 1 $\alpha, 25$-dihydroxyvitamin D3 and resolvin D1 retune the balance between amyloid- $\beta$ phagocytosis and inflammation in Alzheimer's disease patients. J Alzheimers Dis. 2013, 34(1): 155-70.

91. Cifuentes RA, Murillo-Rojas J. Alzheimer's disease and HLA-A2: linking neurodegenerative to immune processes through an in silico approach. Biomed Res Int. 2014, 2014: 791238.

92. Yang J, Li S, He XB, Cheng C, Le W. Induced pluripotent stem cells in Alzheimer's disease: applications for disease modeling and cell-replacement therapy. Mol Neurodegener. 2016, 11(1): 39.

93. Xinzhong Li, Jintao Long, Taigang He, Robert Belshaw, and James Scott. Integrated genomic approaches identify major pathways and upstream regulators in late onset Alzheimer's disease. Sci Rep. 2015, 5: 12393.

94. Engidawork E, Gulesserian T, Yoo BC, Cairns N, Lubec G. Alteration of caspases and apoptosis-related proteins in brains of patients with Alzheimer's disease. Biochem Biophys Res Commun. 2001, 281(1): 84-93.

95. Reed JC. Mechanisms of apoptosis. Am J Pathol. 2000 Nov;157(5):1415-30.

96. Gopalraj RK, Zhu H, Kelly JF, Mendiondo M, Pulliam JF, Bennett DA, Estus S. Genetic association of low density lipoprotein receptor and Alzheimer's disease. Neurobiol Aging. 2005, 26(1): 1-7.

97. Bowen RL, Isley JP, Atkinson RL. An association of elevated serum gonadotropin concentrations and Alzheimer disease? J Neuroendocrinol. 2000, 12(4): 351-4. 
656 98. Vingtdeux V, Davies P, Dickson DW, Marambaud P. AMPK is abnormally activated in 657 tangle- and pre-tangle-bearing neurons in Alzheimer's disease and other tauopathies. Acta $658 \quad$ Neuropathol. 2011, 121(3): 337-49.

659 99. Greco SJ, Sarkar S, Johnston JM, Tezapsidis N. Leptin regulates tau phosphorylation and 660 amyloid through AMPK in neuronal cells. Biochem Biophys Res Commun. 2009, 380(1): $66198-104$.

662 100. Salminen A, Kaarniranta K, Haapasalo A, Soininen H, Hiltunen M. AMP-activated protein 663 kinase: a potential player in Alzheimer's disease. J Neurochem. 2011, 118(4): 460-74.

664 101. Semagacestat | Alzforum. Retrieved April 8, 2019, from

665 https://www.alzforum.org/therapeutics/semagacestat.

666 102. Verubecestat | Alzforum. Retrieved April 8, 2019, from

667 https://www.alzforum.org/therapeutics/verubecestat.

668 103. Atabecestat | Alzforum. Retrieved April 8, 2019, from

669 https://www.alzforum.org/therapeutics/atabecestat.

670 104. Chang Y, Paramasivam M, Girgenti MJ, Walikonis RS, Bianchi E, LoTurco JJ. RanBPM

671 regulates the progression of neuronal precursors through M-phase at the surface of the 672 neocortical ventricular zone. Dev Neurobiol. 2010, 70(1): 1-15.

673 105. Tufail Y, Cook D, Fourgeaud L, Powers CJ, Merten K, Clark CL, Hoffman E, Ngo A, 674 Sekiguchi KJ, O'Shea CC, et al. Phosphatidylserine Exposure Controls Viral Innate Immune 675 Responses by Microglia. Neuron. 2017, 93(3): 574-586.e8.

676 106. Rojiani MV, Alidina J, Esposito N, Rojiani AM. Expression of MMP-2 correlates with 677 increased angiogenesis in CNS metastasis of lung carcinoma. Int J Clin Exp Pathol. 2010, $678 \quad 3(8): 775-81$. 


\section{Table 1 (on next page)}

Databases used in the construction of miRDRN and data usage 
1

\begin{tabular}{|c|c|c|c|}
\hline Database & Information used & Where used & Reference \\
\hline HMDD 2.0 & $\begin{array}{l}\text { Disease-miRNA association, } \\
\text { miRNA-target association }\end{array}$ & Query interface (disease selection) & [16] \\
\hline TarBase & miRNA-target association & $\begin{array}{l}\text { Query interface (miRNA/siRNA } \\
\text { selection) }\end{array}$ & {$[17]$} \\
\hline 7.0 & miRNA-target validation & $\begin{array}{l}\text { Query interface (filter - miRNA-target } \\
\text { validation) }\end{array}$ & \\
\hline $\begin{array}{l}\text { NCBI- } \\
\text { UniGene }\end{array}$ & Gene-tissue association & Query interface (filter - tissue) & {$[18]$} \\
\hline KEGG & Biological pathways & Query interface (filter - pathway) & [19] \\
\hline TAG & Gene-tumor association & Query interface (filter - tumor genes) & [20] \\
\hline $\begin{array}{l}\text { NCBI- } \\
\text { GeneBank }\end{array}$ & Gene ID, TF and/or RC & Query interface (filter - TF and/or RC) & [18] \\
\hline $\begin{array}{l}\text { NCBI- } \\
\text { OMIM }\end{array}$ & OMIM ID & $\begin{array}{l}\text { Target genes; genes on regulatory } \\
\text { network (activated by mouse-click) }\end{array}$ & {$[18]$} \\
\hline BioGRID & Protein-protein interaction & $\begin{array}{l}\text { Construction of regulatory sub- } \\
\text { pathways }\end{array}$ & {$[21]$} \\
\hline GO & $\begin{array}{l}\text { Biological processes, } \\
\text { molecular functions; gene } \\
\text { ontology, gene annotation } \\
\text { and product }\end{array}$ & $\begin{array}{l}\text { Computation of Jaccard index for } \\
\text { regulatory sub-pathways; annotation of } \\
\text { genes on regulatory network (activated } \\
\text { by mouse-click) }\end{array}$ & {$[22]$} \\
\hline
\end{tabular}


Table 2 (on next page)

Data contained in current version miRDRN 
1

$\begin{array}{ccccc}\text { Type of data } & \text { Disease } & \text { miRNA } & \text { miRNA regulated gene } & \text { Target-specific RSP } \\ \text { Number } & 116 & 207 & 389 & 6,973,875\end{array}$

2

3 


\section{Table 3 (on next page)}

Comparison of miRDRN with other miRNA related databases 


\begin{tabular}{|l|c|c|c|c|c|c|}
\hline \multicolumn{1}{|c|}{ Database } & miRDRN & $\begin{array}{c}\text { HMDD } \\
{[17]}\end{array}$ & $\begin{array}{c}\text { TarBase } \\
{[19]}\end{array}$ & $\begin{array}{c}\text { PhenomiR } \\
{[24]}\end{array}$ & $\begin{array}{c}\text { miRwayDB } \\
{[25]}\end{array}$ & $\begin{array}{c}\text { miRPathDB } \\
{[26]}\end{array}$ \\
\hline $\begin{array}{l}\text { Disease-associated } \\
\text { miRNA }\end{array}$ & Yes & Yes & - & Yes & Yes & - \\
\hline $\begin{array}{l}\text { miRNA-associated } \\
\text { target gene }\end{array}$ & Yes & Yes & Yes & - & Yes & Yes \\
\hline $\begin{array}{l}\text { Target gene-KEGG } \\
\text { association }\end{array}$ & Yes & - & - & - & - & Yes \\
\hline $\begin{array}{l}\text { Pathway-associated } \\
\text { miRNA }\end{array}$ & Yes & - & - & - & - & - \\
\hline $\begin{array}{l}\text { Target-specific } \\
\text { regulatory sub- } \\
\text { pathway (RSP) }\end{array}$ & Yes & - & - & - & - & - \\
\hline $\begin{array}{l}\text { Disease-specific } \\
\text { miRNA-protein } \\
\text { regulatory network }\end{array}$ & Yes & - & - & - & - & - \\
\hline $\begin{array}{l}\text { Gene annotation } \\
\text { (GeneBank, TAG. } \\
\text { KEGG, GO) on all } \\
\text { genes on network }\end{array}$ & Yes & - & - & - & - & - \\
\hline $\begin{array}{l}\text { Comorbidity of } \\
\text { disease-pair }\end{array}$ & Yes & - & - & & - \\
\hline
\end{tabular}

1

2

3 


\section{Table 4(on next page)}

Result for sample Single Search: disease, colorectal neoplasm; tissue type, colorectal 
1

\begin{tabular}{|c|c|}
\hline & Disease \\
\hline Disease Name & colorectal neoplasms \\
\hline Tissue Filter & colorectal tumor \\
\hline $\begin{array}{l}\text { Associated miRNAs } \\
\text { (total 33) }\end{array}$ & $\begin{array}{l}\text { hsa-mir-491, hsa-mir-185, hsa-mir-20a, hsa-mir-221, hsa- } \\
\text { mir-199a, hsa-mir-34a, hsa-mir-199b, hsa-mir-34c, hsa- } \\
\text { mir-34b, hsa-mir-148a, hsa-mir-342, hsa-mir-21, hsa-mir- } \\
\text { 499a, hsa-let-7c, hsa-mir-148b, hsa-mir-1915, hsa-mir-17, } \\
\text { hsa-mir-320a, hsa-mir-200c, hsa-mir-143, hsa-mir-139, } \\
\text { hsa-mir-103a, hsa-mir-103b, hsa-mir-107, hsa-mir-497, } \\
\text { hsa-mir-106a, hsa-mir-429, hsa-mir-7, hsa-mir-362, hsa- } \\
\text { mir-330, hsa-mir-367, hsa-mir-339, hsa-mir-133a }\end{array}$ \\
\hline $\begin{array}{l}\text { Targeted genes } \\
\text { (total 37) }\end{array}$ & $\begin{array}{l}\text { BCL2L1, RHOA, CDC42, BNIP2, CDKN1C, AXL, MYC, } \\
\text { BCL2, DNMT1, RHOB, FOXO4, PDCD4, MMP11, } \\
\text { PBX3, CCKBR, CCL20, RND3, NRP1, ZEB1, CTNNB1, } \\
\text { MACC1, IGF1R, DAPK1, KLF4, RAP1B, TGFBR2, } \\
\text { SOX2, YY1, RBL2, E2F1, USF2, PTPN1, RYR3, PLRG1, } \\
\text { RFFL, DNMT3A, KRAS }\end{array}$ \\
\hline $\begin{array}{l}\text { Regulatory sub- } \\
\text { pathways }\end{array}$ & 45565 \\
\hline Distinct genes & 3079 \\
\hline
\end{tabular}

2 


\section{Table 5 (on next page)}

Statistics and gene information in the Network-1, the largest connected sub-network of the CRC-specific miRNA regulatory network 
1

\begin{tabular}{|c|c|c|c|}
\hline & & Number & Item Set \\
\hline & miRNAs & 6 & $\begin{array}{l}\text { hsa-mir-199a, hsa-mir-34a, hsa-mir-199b, hsa- } \\
\text { mir-139, hsa-mir-497, hsa-mir-106a }\end{array}$ \\
\hline & Target genes & 4 & AXL, IGF1R, RAP1B, TGFBR2 \\
\hline 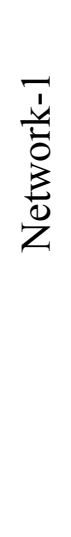 & $\begin{array}{l}\text { Gene Set } \\
\text { (including } \\
\text { target } \\
\text { genes) }\end{array}$ & 56 & $\begin{array}{l}\text { AXL, CSK, TNK2, LCK, PRKACA, FGR, } \\
\text { MAPK15, IGF1R, MERTK, ERBB2, PTK2, } \\
\text { EGFR, JAK2, JAK1, PRKCD, TEC, EPHB2, } \\
\text { PHKG2, ROR1, FES, MAP3K12, RAP1B, } \\
\text { MST4, PAK1, LRRK1, MAP2K3, CDK11B, } \\
\text { ACVR1, TGFBR2, RIOK2, TGFBR1, MAP3K7, } \\
\text { NEK8, NUAK2, OXSR1, CDK1, ACVRL1, } \\
\text { MKNK2, STK35, CDK17, EIF2AK4, DAPK2, } \\
\text { EIF2AK1, TSSK4, ZAK, MAP2K6, SIK3, } \\
\text { VRK2, PINK1, TAOK2, TNIK, MAPK6, } \\
\text { PRKACB, WNK1, PAK6, PKMYT1 }\end{array}$ \\
\hline
\end{tabular}

2

3 


\section{Table 6(on next page)}

Known, literature supported, and potential novel CRC-related genes

*Known target genes used in treatment of CRC. 
1

\begin{tabular}{|c|c|c|c|}
\hline \multirow{4}{*}{ 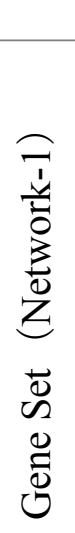 } & & Number & Item Set \\
\hline & $\begin{array}{l}\text { Known CRC } \\
\text { genes }\end{array}$ & 22 & $\begin{array}{l}\text { AXL, LCK, FGR, IGF1R, MERTK, ERBB2, } \\
\text { PTK2, EGFR, JAK2, JAK1, EPHB2, FES, } \\
\text { PAK1, MAP2K3, ACVR1, TGFBR2, TGFBR1, } \\
\text { CDK1, EIF2AK4, DAPK2, MAP2K6, PAK6 }\end{array}$ \\
\hline & $\begin{array}{c}\text { Reference } \\
\text { supported } \\
{[28-55]}\end{array}$ & 26 & $\begin{array}{l}\text { CSK, TNK2*, MAPK15, PRKCD, TEC, PHKG2, } \\
\text { ROR1, RAP1B, MST4, CDK11B, MAP3K7, } \\
\text { NEK8, NUAK2, ACVRL1, MKNK2, STK35, } \\
\text { ZAK, SIK3, VRK2, PINK1, TAOK2, TNIK*, } \\
\text { MAPK6, PRKACB, PKMYT1, WNK1 }\end{array}$ \\
\hline & $\begin{array}{l}\text { Potential } \\
\text { novel cancer- } \\
\text { related gene }\end{array}$ & 8 & $\begin{array}{l}\text { PRKACA, MAP3K12, LRRK1, RIOK2, OXSR1, } \\
\text { CDK17, EIF2AK1, TSSK4 }\end{array}$ \\
\hline
\end{tabular}

2

3 
Table 7 (on next page)

Results for the AD-T2D comorbidity study 
1

\begin{tabular}{lccc}
\hline & Disease 1 & Disease 2 & Comorbidity \\
\hline Disease Name & AD & T2D & AD/T2D \\
\hline Tissue Filter & brain & pancreas & brain/pancreas \\
\hline $\begin{array}{l}\text { Associated- } \\
\text { miRNA }\end{array}$ & $\begin{array}{l}\text { hsa-mir-29a, } \\
\text { hsa-mir-195, } \\
\text { hsa-mir-146a }\end{array}$ & hsa-mir-144 & $\begin{array}{c}\text { hsa-mir-29a, } \\
\text { hsa-mir-195, } \\
\text { hsa-mir-146a, } \\
\text { hsa-mir-144 }\end{array}$ \\
\hline Targeted gene & NAV3, BACE1, & IRS1 & NAV3, BACE1, CFH, \\
CFH & 644 & 3908 & IRS1 \\
\hline $\begin{array}{l}\text { Regulatory sub- } \\
\text { pathways }\end{array}$ & 633 & 2187 & 2352 \\
\hline $\begin{array}{l}\text { Total no. of genes } \\
\text { No. of common } \\
\text { genes }\end{array}$ & - & - & 500 \\
\hline
\end{tabular}

2

3 


\section{Table 8(on next page)}

Known, literature supported, and potential novel AD-T2D comorbid genes

The 210 known AD target genes were built by integrating gene lists from AlzGene (http://www.alzforum.org/genetics) [62], AlzBIG (http://alz.big.ac.cn/) [63] and AlzBase (http://alz.big.ac.cn/alzBase/home) [57]; the 497 known T2D targets were from T-HOD (http://bws.iis.sinica.edu.tw/THOD/) [58]. *Known AD and T2D target; \# No literature support. 


\begin{tabular}{|c|c|c|c|}
\hline & & $\begin{array}{l}\text { No. of targets in } \\
\text { comorbidity gene } \\
\text { set }(500)\end{array}$ & $\begin{array}{c}\text { Comorbid Genes (references in square } \\
\text { brackets) }\end{array}$ \\
\hline 胥 & $\begin{array}{l}\text { Known AD } \\
\text { target } \\
(210)\end{array}$ & 8 & $\begin{array}{l}\text { ALOX5 [59-61], APP*, BIN1 [64], CHGB } \\
\text { [65], VWF*, NEFL }[66,67], \text { LETMD1*, } \\
\text { CELF1 }[68,69]\end{array}$ \\
\hline 全 & $\begin{array}{l}\text { Known } \\
\text { T2D target } \\
(497)\end{array}$ & 14 & $\begin{array}{l}\text { TCF7L2 [70-73], APOA1 [74-76], VWF*, } \\
\text { CDKN2B [77], CAT [78-80], ITGB2 [81,82], } \\
\text { ISL1 [83], POLD3\# APP*, NFKBIB [84], } \\
\text { GNA12\#, DEDD [85,86], LDLR }[87,88], \\
\text { PRKAB1 [89-91] }\end{array}$ \\
\hline
\end{tabular}

1

2 


\section{Figure 1}

Regulatory sub-pathways

In the linked sequence $\left(M, T, G_{1}, G_{2}\right)$, called a miRNA-specific regulatory sub-pathway (MRSP), $M$ is a miRNA, $T$ is its regulatory target gene, $G_{1}$ is a protein interacting (according to PPI data) with $T$, and $G_{2}$ is a protein interacting with $G_{1}$. In the text the sequence $\left(T, G_{1}, G_{2}\right)$ is called a target-specific regulatory sub-pathway, or simply, regulatory sub-pathway (RSP).

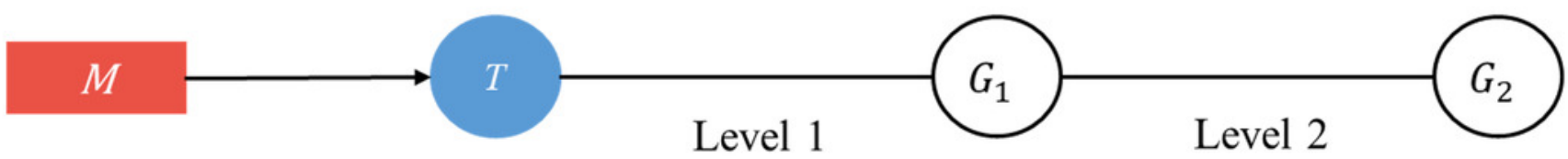

M MiRNA

G) Gene $\quad-$ Protein-protein interaction pair 


\section{Figure 2}

Schematic construction of disease-specific miRNA regulatory network (RRN)

For a given disease there may be more than one miRNA associated with it, and each diseaseassociated miRNA may have one or more target genes. After all the miRNA-specific RSPs having the from $\left(M, T, G_{1}, G_{2}\right)$ are constructed (in the case of miRDRN utilization, retrieved from its database), an RRN is built from entire set of MRSPs by linking all unlinked pairs of genes/proteins if they have interaction according to BioGRID.

a) Disease-associated miRNAs. b) Extension of the regulatory network with miRNA-target gene.

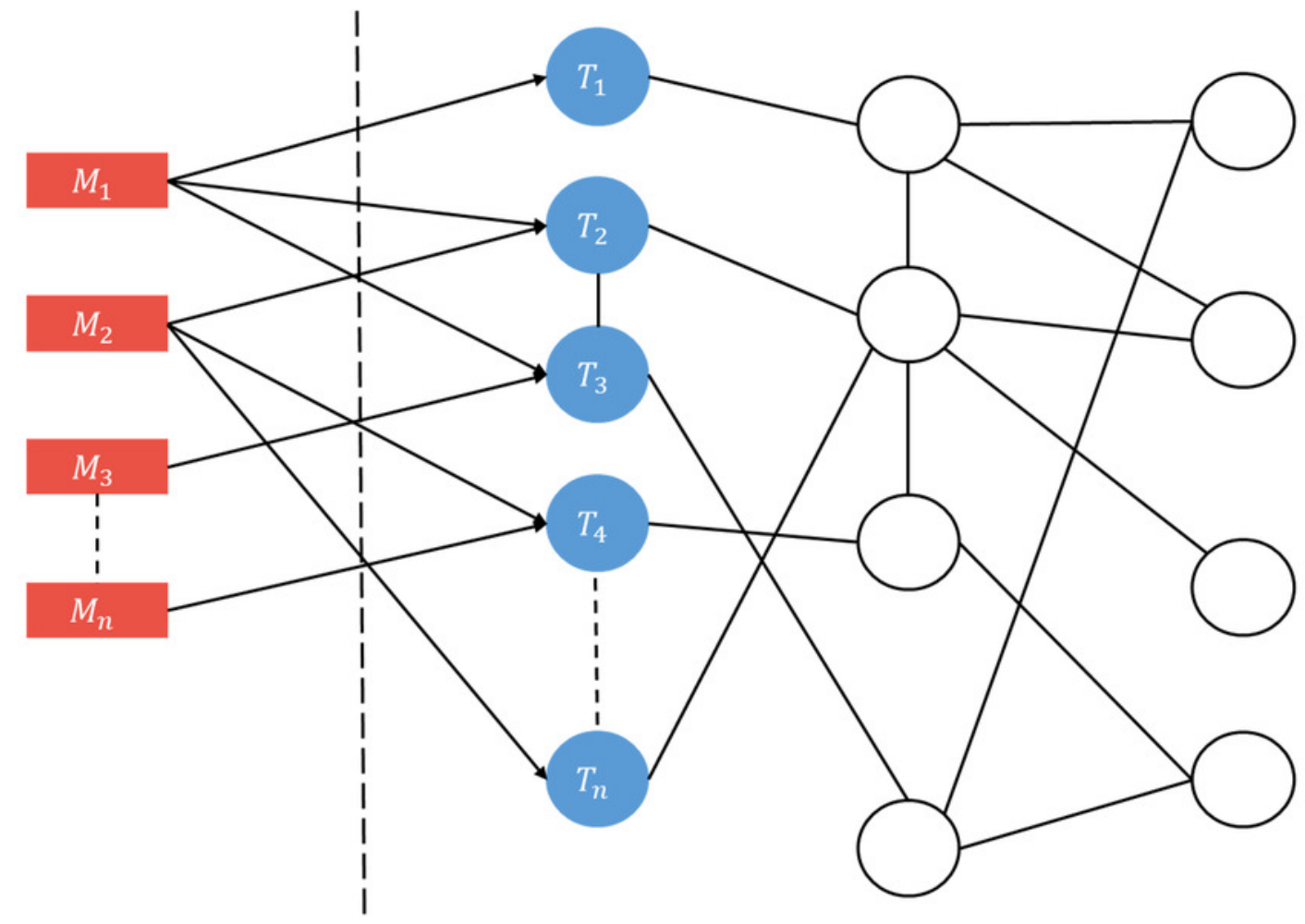




\section{Figure 3}

\section{Entry interface of miRDRN}

User may select "Single Search" to explore a single disease, miRNA, or siRNA, or "Comorbidity Search" to explore a disease-pair.

miRDRN 8
Comorbidity Search

Single Search

Contact Us

miRDRN (miRNA Disease Regulatory Network) is a useful platform for

discovering potential novel disease networks and comorbidity genes by disease-

associated miRNAs targeting pathways. Meanwhile, we provide a powerful

visualization tool to present information.

We offer all possible sub-pathways from miRNA target protein by using proteinprotein interactions. Our database integrated various data sources such as Diseaseassociated miRNAs, miRNA-associated targeted gene, Tumor-associated gene.

Gene annotation and expression data.

version 1.0

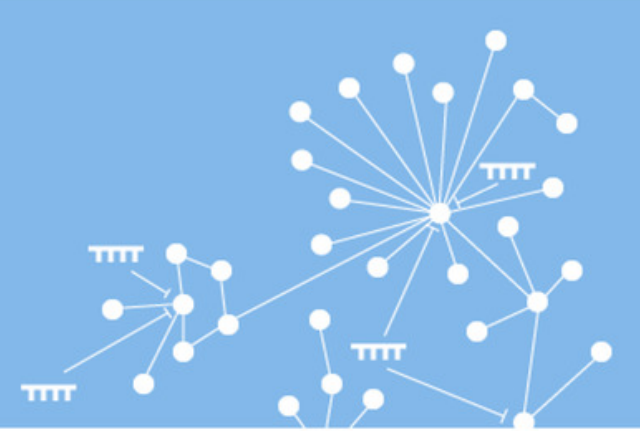

\section{Statistics}

Protein Entries

Protein-Protein Interactions

Disease Association

KEGG Pathways

miRNA Entries

siRNA Entries
15,901

165,502

380

274

932

11,221

\section{Visualization}

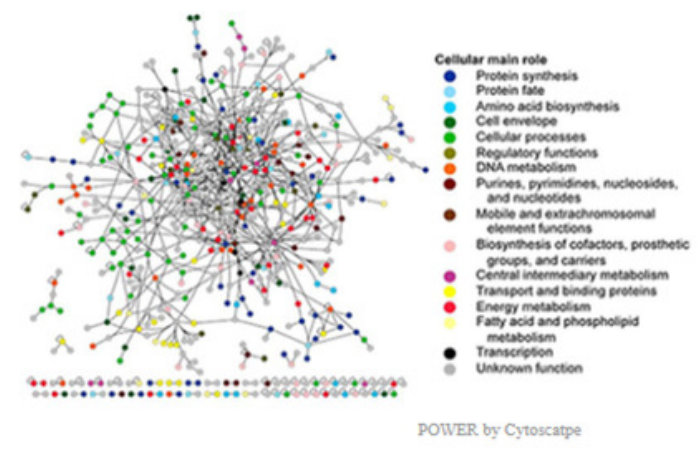




\section{Figure 4}

Query interface of Single Search

User is required to select a disease (or miRNA/siRNA) and other filters/options. As shown in the figure, the disease "Colorectal Neoplasms" with the optional tissue type "colorectal tumor" are selected. Other selections require target experimental validation to be "positive" and "direct", targets restricted to be cancer related genes, pathway ranked by Jaccard scores on molecular functions (MF), and $p$-value less than 0.001 . 

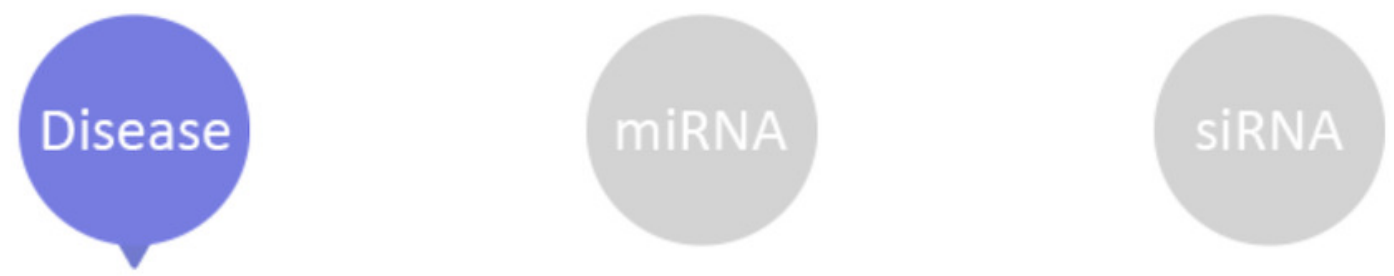

\section{Colorectal Neoplasms}

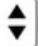

\section{Filters}

miRNA target experimental validation is "positive" and "direct" (TarBase v7.0) $₫$ TRUE (optional):

Tissue/Tumor type : colorectal tumor

Common expression of target gene, gene 1 and gene 2 nodes in KEGG (optional):

Filters on target-specific subYes pathways

Target Gene Gene $1 \quad$ Gene 2

Admit only cancerous protein (optional): Cancer related gene (CRG) Oncogene (OCG) Tumor suppressor gene (TSG)

Filter out receptor protein (optional):

Admit only transcription factor (optional):

Pathway ranking by:

Jaccard index (MF) $* \mathrm{P}$-Value $<0.001$

(ex:0.001)

\section{Query}




\section{Figure 5}

Result interface on miRNAs and target genes (for Colorectal Neoplasms/colorectal tumor)

Search result, based on query input shown in Figure4, on miRNAs and literature source (blue area) and target genes (green). For each gene the gene symbol and its OMIM id are given, as well as information on whether the protein it encodes has a cancerous protein tag: CRG, cancer related gene; OCG, oncogene; TSG, tumor suppressor gene. 


\section{Associated miRNAs}

Total: 20

miRNA

Pubmed

21186079, 21242194, 21278784, 21317930, 21329882, 21565830,

hsa-mir-185, hsa-mir-20a, hsa-mir-221, hsa-mir-34a, hsa-mir-34c, hsa-mir-34b, hsa-mir-342, hsamir-21, hsa-let-7c, hsa-mir-17, hsa-mir-200c, hsa-mir-320a, hsa-mir-139, hsa-mir-103a, hsa-mir21872591, 21984339, 22099878, 22132820, 22407310, 22459450, 22580051, 22593189, 22710713, 22912877, 23208495, 23250421, 107, hsa-mir-497, hsa-mir-106a, hsa-mir-7, hsa-mir-362, hsa-mir-339

23280316, 23696794

\section{Target genes by miRNAs}

\section{Total: 23}

\begin{tabular}{llll}
\hline Gene & Cancerous protein & OMIM ID & miRNAs \\
\hline RHOA & CRG & 165390 & hsa-mir-185 \\
\hline CDC42 & & 116952 & hsa-mir-185 \\
\hline BNIP2 & hsa-mir-20a \\
\hline CDKN1C & TSG & 603292 & $601679,604318,194050,600856$, \\
\hline AXL & hsa-mir-221 \\
\hline MYC & OCG & 103280,605564 & hsa-mir-34a \\
\hline DNMT1 & & 109135 & hsa-mir-34c, hsa-mir-34b \\
\hline RHOB & OCG & 190080,605235 & hsa-mir-342 \\
\hline PBX3 & CRG & 126375 & hsa-mir-21 \\
\hline CCL20 & & 165370 & hsa-let-7c \\
\hline RND3 & & 176312 & hsa-mir-21 \\
\hline ZEB1 & & 601960 & hsa-mir-17 \\
\hline CTNNB1 & 602924 & hsa-mir-200c \\
\hline IGF1R & 189909 & hsa-mir-320a \\
\hline DAPK1 & OCG & 116806 & hsa-mir-139, hsa-mir-497 \\
\hline KLF4 & & 147370 & hsa-mir-103a, hsa-mir-107 \\
\hline TGFBR2 & TSG & 600831 & hsa-mir-103a, hsa-mir-107 \\
\hline YY1 & OCG & 602253 & hsa-mir-106a \\
\hline RBL2 & TSG & 190182 & hsa-mir-7 \\
\hline E2F1 & & 600013 & hsa-mir-17 \\
\hline USF2 & TSG & 602536,180203 & hsa-mir-362 \\
\hline PTPN1 & 189971 & hsa-mir-362 \\
\hline PLRG1 & TSG & 600390 & hsa-mir-362 \\
\hline
\end{tabular}




\section{Figure 6}

Result interface on target-specific RSPs (for Colorectal Neoplasms/ colorectal tumor)

RSPs are listed in descending order (column 1) by p-value (column 6). Columns 2-4 give the symbols of genes in the sequence $\left(T, G_{1}, G_{2}\right)$. Column 5 gives known pathways, such as a KEGG pathway, of which $\left(T, G_{1}, G_{2}\right)$ is a part. On first appearance, all RSPs (2111 in this example) are listed on multiple pages. Three options allow restricting the output to a smaller set: "Gene filter", where user can restrict the set to only those RSPs containing a specified gene, similarly "KEGG filter", and "Show top ... sub-pathways", where user can ask for only the top-N RSPs having the smallest $p$-values be listed and used for network construction. 


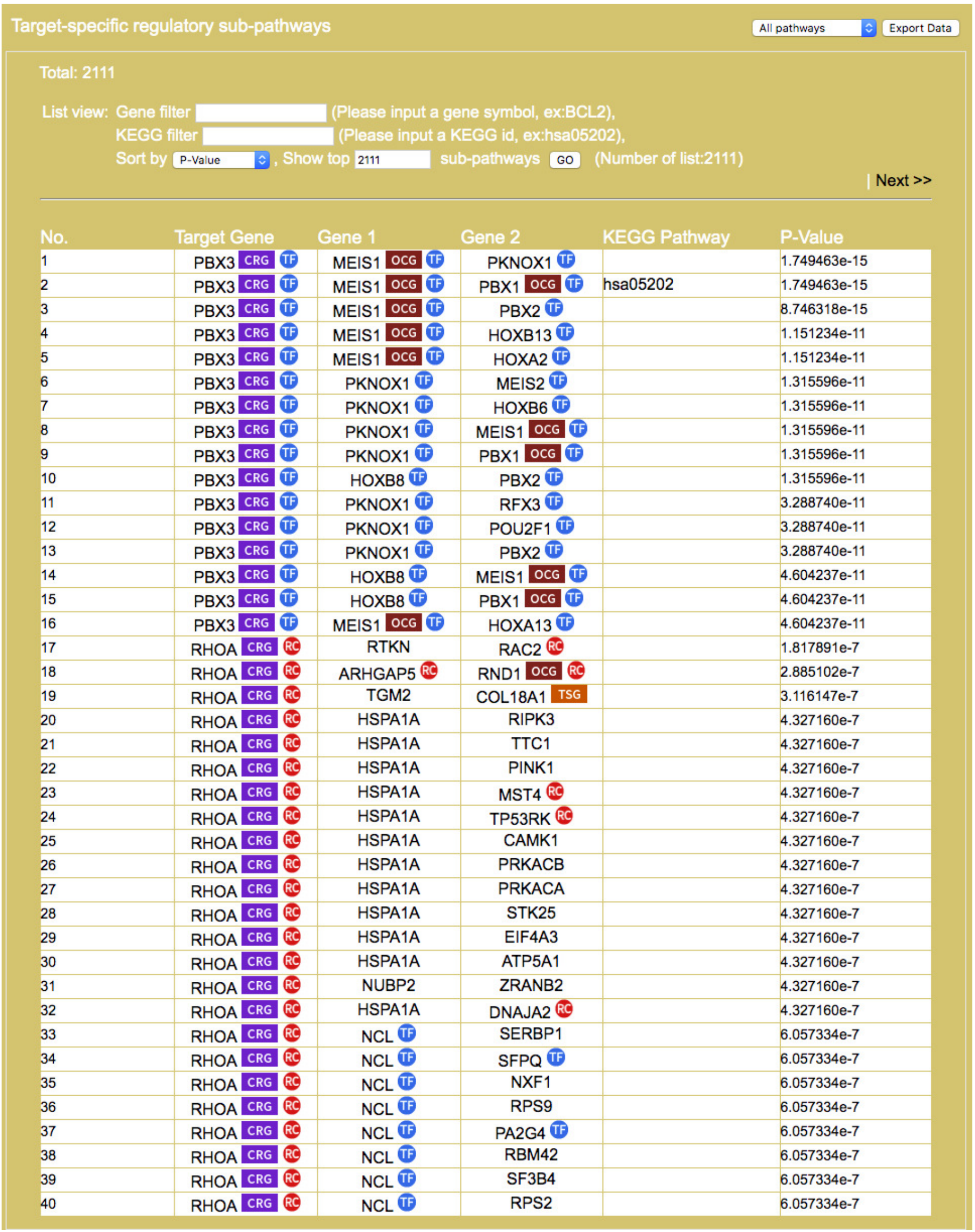




\section{Figure 7}

\section{Result on comorbidity genes in Alzheimer's Disease-Type 2 Diabetes Comorbidity Search}

Genes common to some RSPs of both diseases are listed, together with information on cancer genes status, OMIM Id, and KEGG pathway.

\begin{tabular}{|c|c|c|c|c|}
\hline No. & Gene & $\begin{array}{l}\text { Cancerous } \\
\text { protein }\end{array}$ & OMIM ID & KEGG \\
\hline 1 & $\mathrm{~A} 2 \mathrm{M}$ & & 103950 & hsa04610 \\
\hline 2 & ABCF1 & & 603429 & \\
\hline 3 & $\mathrm{ACHE}$ & & 100740 & hsa00564, hsa04725 \\
\hline 4 & ACO1 & & 100880 & hsa00020, hsa00630, hsa00300 \\
\hline 5 & AFG3L1P & & 603020 & \\
\hline 6 & ALOX5 & & 152390 & $\begin{array}{l}\text { hsa04726, hsa05145, hsa00590, } \\
\text { hsa04913 }\end{array}$ \\
\hline 7 & BIN1 & TSG & 601248 & \\
\hline 8 & ANXA11 & & 602572 & \\
\hline 9 & APBB1 & & 602709 & hsa05010 \\
\hline 10 & APBB2 & & 602710 & \\
\hline 11 & APLP1 & & 104775 & \\
\hline 12 & APOA1 & & 107680 & $\begin{array}{l}\text { hsa03320, hsa04977, hsa04975, } \\
\text { hsa05143 }\end{array}$ \\
\hline 13 & APP & & $605378,100070,104760$ & hsa04726, hsa05010 \\
\hline 14 & ARL4D & & 600732 & \\
\hline 15 & ASS1 & & 603470 & hsa00250, hsa00330 \\
\hline 16 & RERE & & 605226 & \\
\hline 17 & ATP5A1 & & 164360 & $\begin{array}{l}\text { hsa05012, hsa05016, hsa00190, } \\
\text { hsa05010 }\end{array}$ \\
\hline 18 & ALDH7A1 & & 107323 & $\begin{array}{l}\text { hsa00260, hsa00380, hsa00330, } \\
\text { hsa00280, hsa00410, hsa00300, } \\
\text { hsa00561, hsa00310, hsa00340, } \\
\text { hsa00640, hsa00053, hsa00620, } \\
\text { hsa00071, hsa00010 }\end{array}$ \\
\hline 19 & ATP6V1E1 & & 108746 & $\begin{array}{l}\text { hsa05110, hsa04966, hsa05323, } \\
\text { hsa04721, hsa05120, hsa00190, } \\
\text { hsa04145 }\end{array}$ \\
\hline 20 & BLMH & & 602403 & \\
\hline 21 & BNIP1 & & 603291,612478 & hsa04130 \\
\hline 22 & BTF3 & & 613595 & \\
\hline 23 & MRPL49 & & 606866 & \\
\hline 24 & CARS & & 123859 & hsa00970 \\
\hline 25 & CAT & & 115500,607424 & $\begin{array}{l}\text { hsa05014, hsa00380, hsa00630, } \\
\text { hsa04146 }\end{array}$ \\
\hline
\end{tabular}




\section{Figure 8}

Display of a sub-RRN built from a subset of RSPs determined by the user using options available in the interface shown in Figure 6

The option "Show top-70" RSPs (by p-value) was used. When the mouse is placed on a node (in this case the gene IRS1) in the displayed network, a small pop-up window opens to show the name of the node/gene and the number of other nodes it is linked to, and annotation on the node from GO, OMIM, KEGG, and GeneBank databases. 
Disease specific miRNAs regulated network
Cancerous gene :
$\checkmark / O C G$
$\triangle /$ TSG
$\square$ / BOTH
Color labeling :
I miRNA
- / Target Gene / Comorbidity Gene

Layout : Radial

$\mathbf{v}$

If you re-setting the sub-pathways list view, please select this layout again)
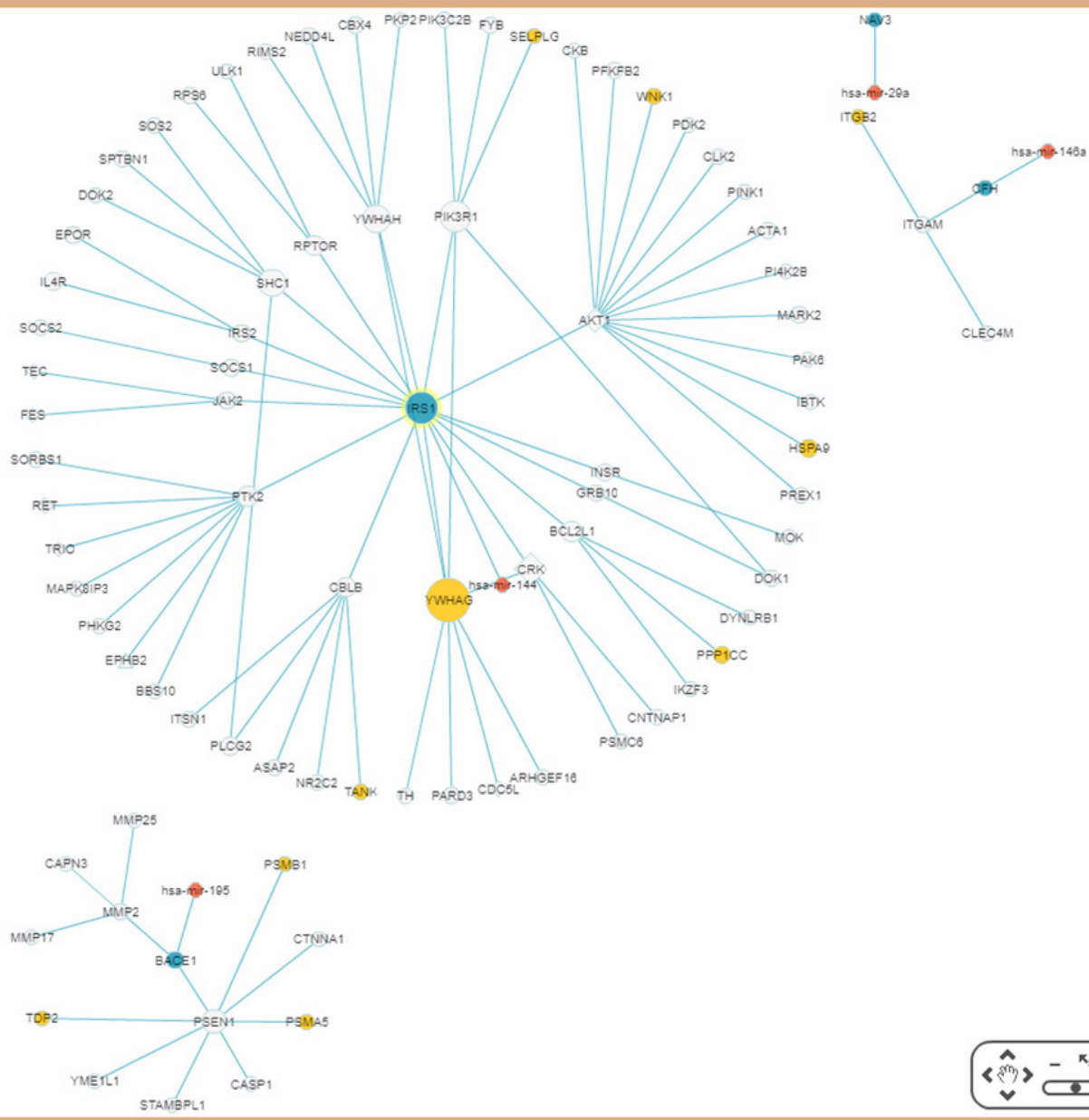

information for selected node:

Gene:

Cancerous protein

OMIM ID:

KEGG pathway
IRS1

147545

hsa04722 Neurotrophin signaling pathway - Homo sapiens (human)

hsa04151 PI3K-Akt signaling pathway - Homo sapiens (human)

hsa04930 Type II diabetes mellitus - Homo sapiens (human)

hsa04150 mTOR signaling pathway - Homo sapiens (human)

hsa04920 Adipocytokine signaling pathway - Homo sapiens (human)

ellular component

Biological process

Molecular function

\begin{tabular}{|c|c|c|}
\hline \multicolumn{2}{|c|}{ Cellular component } & Molecular function \\
\hline GO:0005901 & caveola & \\
\hline GO:0005829 & cytosol & \\
\hline GO:0005899 & insulin receptor complex & \\
\hline GO:0005634 & nucleus & \\
\hline GO:0005737 & cytoplasm & \\
\hline GO:0005886 & plasma membrane & \\
\hline
\end{tabular}


Figure 9

A partial miRNA regulatory network (RRN) for colorectal neoplasm

The RRN is constructed from the top 70 RSPs by $p$-value for colorectal neoplasm, tissue type, colorectal tumor. A link indicates a miRNA-target relation or a PPI; red circle, miRNA; blue circle, miRNA target gene; yellow circle, non-target gene; diamond, oncogene; triangle, tumor suppressor gene.

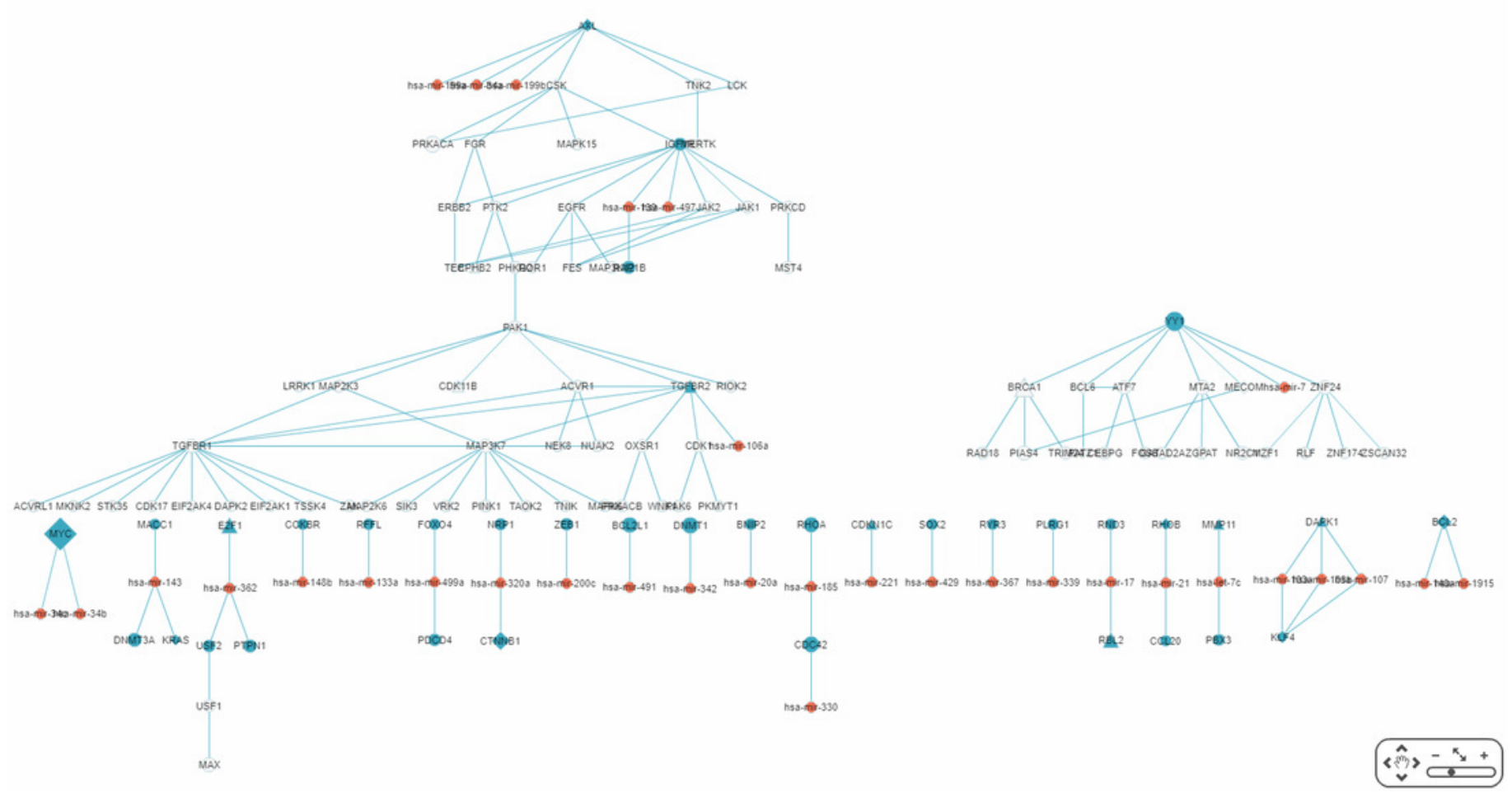




\section{Figure 10}

The sub-RRN Network-1

This largest connected sub-RRN for colorectal neoplasm (constructed from the top 70 RSPs by $p$-value), containing six miRNAs targeting four genes connected to 52 other genes, is itself composed of two parts, one 28 nodes (five miRNAs targeting three genes) and the other 34 nodes (one miRNA targeting one gene), connected by a single link.

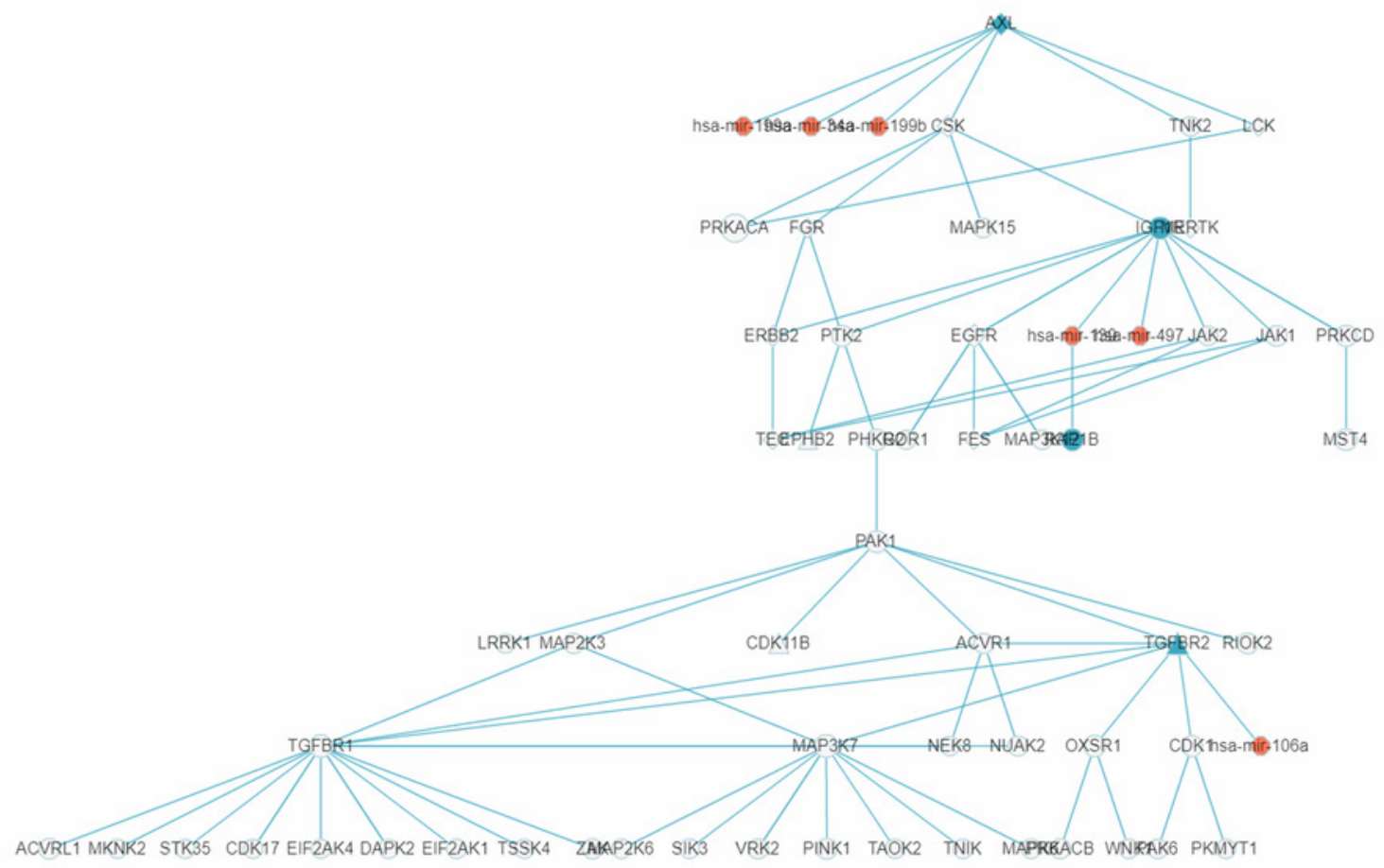


Figure 11

A sub-RRN of CRC obtained by using TNK2 as a gene filter

The RRN contains the target gene $A X L$ regulated by three miRNAs, hsa-mir-199b, hsamir-34a, hsa-mir-199a, and linked by PPI to TNK2, itself linked by PPI to four other genes AXL(OCG), MAGI3, HSP9OAB2P, MERTK(OCG), KAT8.

miRNA regulated sub pathways

Total: 45565

List view: Gene filter TNK2

Sort by P-Value
(Please input a gene symbol, ex:BCL2)

sub-pathways $\mathrm{GO}$ (Number of list 4 )

Next $>>$

\begin{tabular}{|c|c|c|c|c|c|}
\hline No. & Target Gene & Gene 1 & Gene 2 & Common Pathway & P-Value \\
\hline 1 & AXL OCG $B C$ & TNK2 ${ }^{\mathrm{BC}}$ & MERTK OCG ${ }^{2 C}$ & & $2.998519 \mathrm{e}-18$ \\
\hline 2 & AXL OCG ${ }^{2} C$ & TNK2 ${ }^{\circledR C C}$ & HSP90AB2P & & $7.875431 \mathrm{e}-7$ \\
\hline 3 & AXL OCG ${ }^{2}$ & TNK2 RC & MAGI3 RC & & $1.574368 \mathrm{e}-6$ \\
\hline 4 & $A X L$ OCG $\mathbb{B C}$ & TNK2 ${ }^{\circledR C}$ & KAT8 & & $1.438571 e-5$ \\
\hline
\end{tabular}

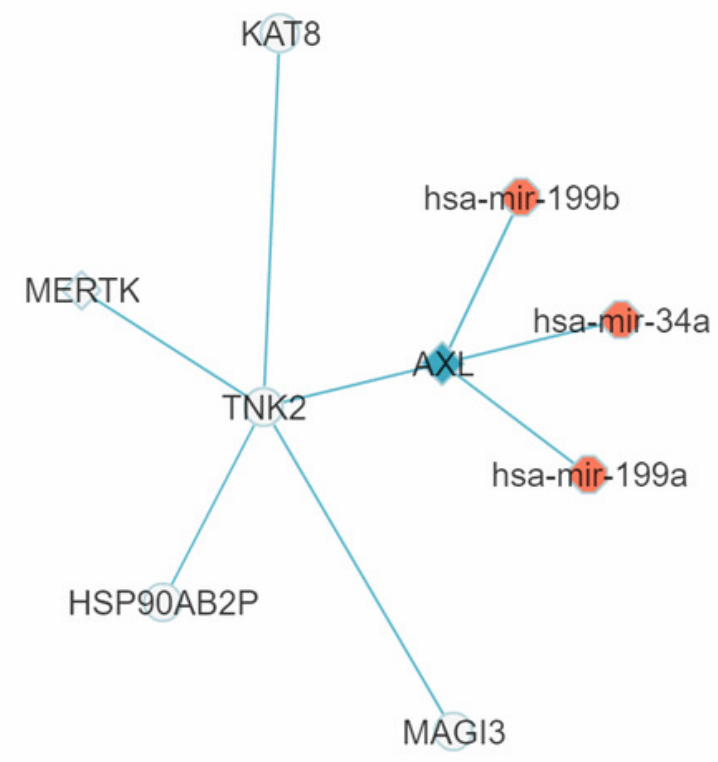

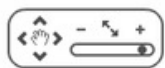


Figure 12

A miRNA regulatory sub-network centered on the AD-associated gene BACE1

The genes PSEN1, NCSTN, RANBP9, PLSCR1, MMP2, and FURIN are shown to be immediately downstream to, i.e., have level 1 PPI with, BACE1.

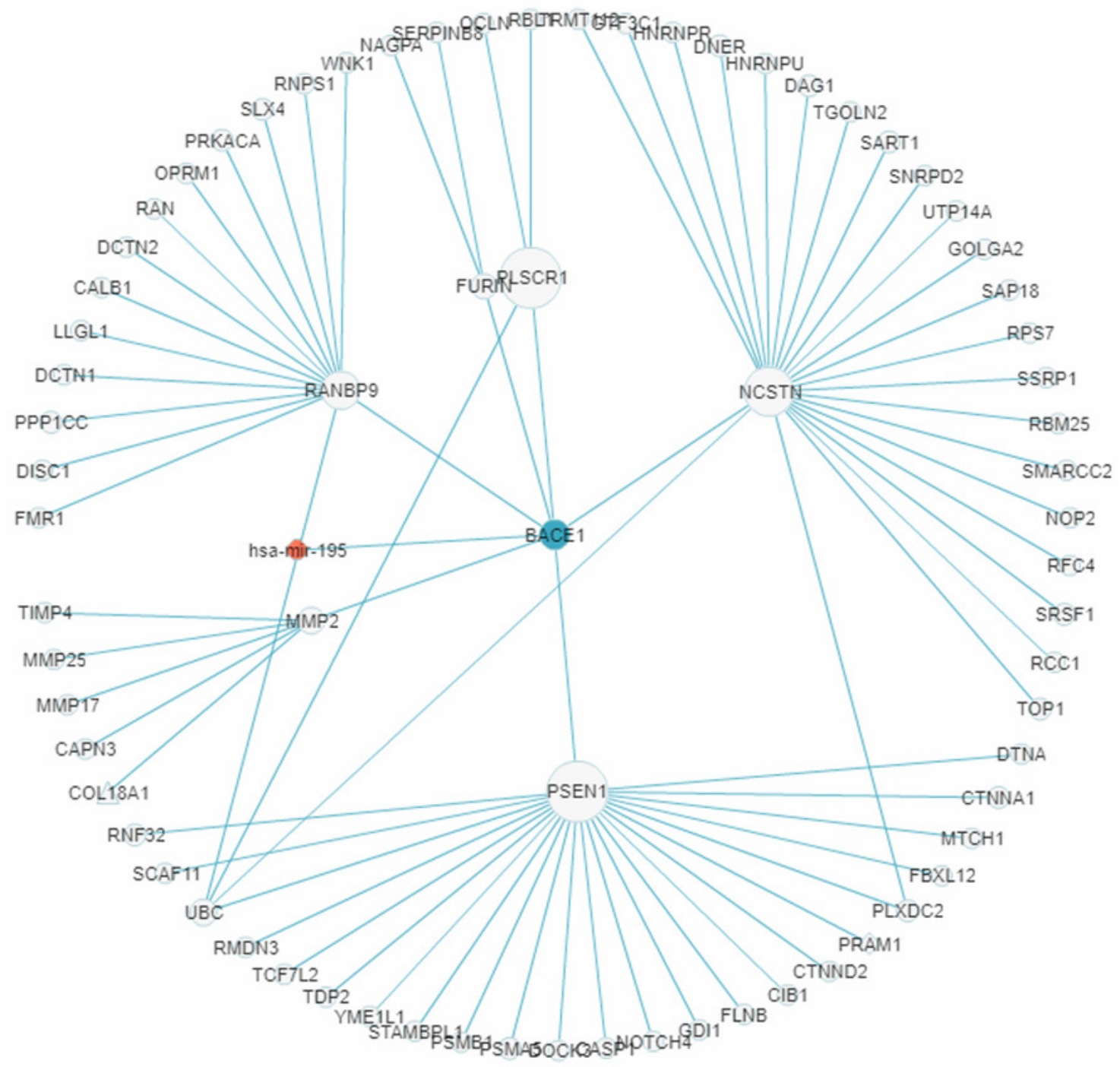

